Fall 2006

\title{
"The Pride of Indiana": An Empirical Study of the Law School Experience and Careers of Indiana University School of Law- Bloomington Alumni
}

\author{
Kenneth G. Dau-Schmidt \\ Indiana University Maurer School of Law, kdauschm@indiana.edu \\ Jeffrey E. Stake \\ Indiana University Maurer School of Law, stake@indiana.edu \\ Kaushik Mukhopadhaya \\ Center for Disease Control \\ Timothy Haley \\ Indiana University School of Law
}

Follow this and additional works at: https://www.repository.law.indiana.edu/ilj

Part of the Legal Education Commons, and the Legal Profession Commons

\section{Recommended Citation \\ Dau-Schmidt, Kenneth G.; Stake, Jeffrey E.; Mukhopadhaya, Kaushik; and Haley, Timothy (2006) "'The Pride of Indiana": An Empirical Study of the Law School Experience and Careers of Indiana University School of Law-Bloomington Alumni," Indiana Law Journal: Vol. 81 : Iss. 4 , Article 13. \\ Available at: https://www.repository.law.indiana.edu/ilj/vol81/iss4/13}

This Study is brought to you for free and open access by the Law School Journals at Digital Repository @ Maurer Law. It has been accepted for inclusion in Indiana Law Journal by an authorized editor of Digital Repository @ Maurer Law. For more information, please contact rvaughan@indiana.edu.

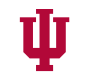

JEROME HALL LAW LIBRARY

INDIANA UNIVERSITY

Maurer School of Law
Bloomington 


\section{"The Pride of Indiana": ${ }^{1}$ An Empirical Study of the Law School Experience and Careers of Indiana University School of Law-Bloomington Alumni}

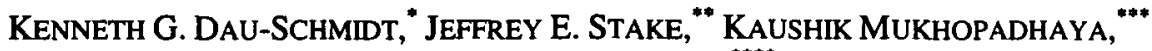
AND TIMOTHY A. HALEY ${ }^{* * *}$

INTRODUCTION

I. “COME AND JOIN IN SONG TOGETHER": ALUMNI REFLECTIONS ON THE INDIANA UNIVERSITY SCHOOL OF LAW-BLOOMINGTON

A. Law School Classes

B. Law School Experience

C. Paying for Law School

D. Career Plans Before and After Law School

II. “AIN'T GOD GOOD TO INDIANA?": THE CAREERS OF INDIANA LAW

ALUMNI.

A. Personal Characteristics that Might Affect a Legal Career or Be Affected by that Career.

B. Type of Practice

C. Income, Hours, Job Satisfaction, and Satisfaction with Work-Family Balance.

D. Regression Analysis of Indiana Law Alumni Income and Job Satisfaction

1. Taken from "Hail to Old I.U.," Indiana University's alma mater, written by T.J. Giles in 1893 [hereinafter "Hail to Old I.U."]. The authors would like to thank Kathryn Zeiler, Leandra Lederman, the participants of the Georgetown University Law and Economics Seminar, and the participants of the IU alumni focus groups who commented on preliminary results and drafts. Preliminary results from this study were presented at the annual meeting of the Midwest Law and Economics Association. Some of the empirical work on this Article was paid for with a grant from the Law School Admissions Council. Professors Dau-Schmidt and Stake dedicate this article to their students, whose intelligence, enthusiasm, and creativity make teaching rewarding, exciting, and fun.

* Willard and Margaret Carr Professor of Labor and Employment Law, Indiana University School of Law-Bloomington. B.A. 1978, University of Wisconsin-Madison; M.A. 1981, J.D. 1981, Ph.D. (Economics) 1984, University of Michigan-Ann Arbor.

** Louis F. Niezer Faculty Fellow, Indiana University School of Law-Bloomington. B.A. 1975, University of Illinois; J.D. 1981, Georgetown University Law Center.

*** Economist, Center for Disease Control, Atlanta, Georgia. B.S. 1990, Indian Statistical Institute-Calcutta; M.S. 1992, Indian Statistical Institute-New Delhi; Ph.D. (Economics) 1999, Indiana University-Bloomington.

**** J.D. Candidate 2006, Indiana University School of Law-Bloomington; B.A. 2002, North Carolina State University-Raleigh. 


\section{INTRODUCTION}

One of the joys of the academic life is participating in the lifecycle of the law school "family." Each fall the halls of the law school resound with the noise and energy of a new entering class. Full of wonderment and excitement, these newest members of the law school family join their academic "siblings" to make new friends, perhaps meet a spouse, and begin their adventures in the life of the law. As with actual children, our time with them is all too short. Although teaching is hard work and some students can try one's patience, given the amount we enjoy getting to know our students and given how much they help us to learn and grow along with them during their education, three years seems far too short for this relationship. Nevertheless, each spring we rejoice in their successes as another third-year class outgrows their need for us and goes on to the rest of their lives and their legal careers.

Although we denizens of the law school get a front row seat to view this procession of academic classes, the proximity of our vantage point does not afford a complete picture of the process, and we are left to wonder about important questions. The professors, of course, only see the process from their perspective. What do the students think of their experiences here at Indiana University? Do they enjoy their time with us? Do they find it stimulating? Is what they learn during their stay at the law school useful to them in their later lives and careers? Even more hidden from us is what happens to them once they leave the protective environs of 211 South Indiana Avenue. Although many of our alumni remain in touch-making a visit for alumni weekend or a reunion, returning to recruit graduates from later classes, advising the law school on our Board of Visitors, or even returning to teach or be dean ${ }^{2}$ - such reports cannot constitute a comprehensive analysis of our graduates' experiences in the greater world. What sort of jobs do they go into? Do they enjoy their work? Do they progress in their careers? How much money do they make? Are they satisfied with the balance in their lives between work and family?

It was to examine precisely such questions, to take a walk in our students' shoes through law school and right out the door, that Professors Dau-Schmidt and Stake devised the Indiana University School of Law-Bloomington Alumni Survey. We have conducted the survey every year for the last five years on the law school's alumni five and fifteen years after graduation. ${ }^{3}$ The survey consists of seventy-one questions concerning the graduates' personal characteristics, family responsibilities, reflections on law school, and career experiences, from which we can generate 104 variables. $^{4}$ Although the survey response rate has varied from year to year, the law school's alumni have been very cooperative in this experiment, returning a total of 593 surveys for an approximately $33 \%$ response rate. ${ }^{5}$ Based on these survey responses, we can

2. Our current dean, Lauren Robel, is a graduate of Indiana's class of 1983.

3. Accordingly, in spring of 2000 we sent surveys to the law school's graduating classes of 1995 and 1985. We have conducted similar surveys each year until the present time.

4. The survey is purposely modeled on the University of Michigan Law Alumni Survey to allow comparative studies between the two data sets.

5. All surveys suffer from response biases, in particular that the more successful among those surveyed tend to be the ones who respond. Generally, the higher the percent of returned surveys, the smaller possible response biases. Our response rate of $33 \%$ is well within the bounds of what is generally experienced and accepted in analyzing such survey results. 
assess what the graduates think of their law school experiences, what careers their education has led to, whether they progress in those careers, whether they enjoy their careers, and how much money they make. With the use of personal characteristics, we can also assess how law school and career experiences vary among our graduates according to gender, race, and ethnicity. Although this information is useful for professors and administrators, it will perhaps be most interesting to students, recent graduates, and alumni. Sharing the experiences of those who have made the leap from law school to the practice of law provides very useful information on the labor market for lawyers, easing the concerns and heightening the excitement of students and recent graduates. Moreover, this data allows alumni who have trod this path together to communicate their experiences in the legal profession. Though responses are anonymous, this data serves as a link between classmates, colleagues, and old friends.

This Article is the first report of the survey's results. It shows that our alumni were active students and are generally very satisfied when they reflect back on their experiences at Indiana. Our alumni found law school particularly satisfying intellectually. Women were especially satisfied with their law school experiences. Students' participation in extracurricular activities and employment may be indicative of their future career plans, as it seems our students chose to participate in activities they believed would help for the particular career they wanted to pursue. We also find that, after graduation, our alumni use their talents and skills to undertake successful careers in a variety of professional settings while attempting to balance work with family life. Traditional gender roles affect family life and career choices: our male alumni focus on earning income while our female alumni assume significantly greater childcare responsibilities. Women, Blacks, and Hispanics tend to be found in greater proportions as government attorneys, public interest attorneys, or as corporate counsel, and the women who go into private practice tend to be found disproportionately in the larger law firms. Women and Blacks reported lower incomes than men-who are predominately found in private practice-although men, women, and Blacks reported similar job satisfaction. Women tend to report higher levels of satisfaction with their families. The personal traits of our graduates and the family choices they make appear to have profound effects on their careers.

\section{I. "COME AND JOIN IN SONG TOGETHER": ${ }^{6}$ ALUMN REFLECTIONS ON THE INDIANA UNIVERSITY SCHOOL OF LAW-BLOOMINGTON}

To begin our walk in the shoes of our alumni, we start with their perceptions of the law school experience. In this Part, we look at the classes our alumni took in school, their overall satisfaction with the law school experience, their methods of financing law school, and the evolution of their career plans before and after law school. Though there have been a number of studies that critically examine legal education, the vast majority of these studies utilized survey responses of current students. ${ }^{7}$ To our

6. "Hail to Old I.U.," supra note 1.

7. These studies typically seek to determine the effects of recently implemented policies or recently questioned presumptions, such as the effectiveness of diversity in legal training. For examples of these types of empirical analyses, see Elizabeth Mertz, Wamucii Njogu \& Susan Gooding, What Difference Does Difference Make? The Challenge for Legal Education, $48 \mathrm{~J}$. LEGAL EDUC. 1 (1998); Adam Neufeld, Costs of an Outdated Pedagogy? Study on Gender at 
knowledge, ours is the first systematic empirical analysis of law school based on alumni reflections. Our hope is that the "real world" experience of our alumni will provide insight and perspective on the law school environment and their experiences here in Bloomington.

\section{A. Law School Classes}

No analysis of the law school experience would be complete without some analysis of alumni classroom experience. For many, the law school class is the most important part of the law school experience and the basic unit for discussion of those experiences. The survey asked each alum to identify the course or courses that he or she found to be (1) especially valuable to his or her career, (2) especially stimulating intellectually, and (3) of greater need in the law school curriculum. The alumni might give no response, one response, or several responses to each of the three questions. Table 1 summarizes these responses. The courses are listed in approximate chronological order, with the courses traditionally taken in the first year appearing at the top of the list, advanced legal courses appearing toward the middle, and the highly specialized courses appearing toward the bottom.

Table 1. Mentions of courses that alumni found valuable to their career, found intellectually satisfying, or would like to see more of in the curriculum

\begin{tabular}{lccc}
\hline Course & Valuable to Career & $\begin{array}{c}\text { Stimulating } \\
\text { Intellectually }\end{array}$ & $\begin{array}{c}\text { Need More in the } \\
\text { Curriculum }\end{array}$ \\
\hline Contracts & 98 & 47 & 12 \\
Civil Procedure & 72 & 14 & 16 \\
Criminal Law & 23 & 38 & 4 \\
Property & 33 & 30 & 17 \\
Torts & 68 & 113 & 3 \\
Research \& Writing & 65 & 6 & 62 \\
Prof. Responsibility & 1 & 3 & 0 \\
Constitutional Law & 24 & 109 & 2 \\
Evidence & 64 & 29 & 10 \\
Criminal Procedure & 21 & 27 & 2 \\
Tax & 38 & 38 & 24 \\
Trial Practice & 16 & 6 & 19 \\
Trial Advocacy & 25 & 5 & 12 \\
Clinic & 18 & 3 & 31 \\
\hline
\end{tabular}

Harvard Law School, 13 AM. U. J. GENDER SOC. POL'y \& L. 511 (2005). For an extensive literature review and discussion of decisions to pursue a legal education and student satisfaction with law school while enrolled, see James R.P. Ogloff, David R. Lyon, Kevin S. Douglas \& V. Gordon Rose, More Than "Learning to Think Like a Lawyer:" The Empirical Research on Legal Education, 34 Creighton L. Rev. 73 (2000). 


\begin{tabular}{|c|c|c|c|}
\hline Course & Valuable to Career & $\begin{array}{l}\text { Stimulating } \\
\text { Intellectually }\end{array}$ & $\begin{array}{l}\text { Need More in the } \\
\text { Curriculum }\end{array}$ \\
\hline Wills \& Trusts & 10 & 11 & 2 \\
\hline Real Estate & 11 & 4 & 10 \\
\hline Land Use Controls & 6 & 2 & 0 \\
\hline Patent \& Trademark & 8 & 3 & 4 \\
\hline Corporations & 44 & 11 & 22 \\
\hline Commercial Law & 7 & 5 & 0 \\
\hline Securities Regulation & 20 & 8 & 6 \\
\hline Antitrust & 3 & 5 & 3 \\
\hline Bankruptcy & 15 & 4 & 4 \\
\hline International Law & 3 & 14 & 4 \\
\hline Administrative Law & 48 & 3 & 10 \\
\hline Family Law & 4 & 2 & 2 \\
\hline Immigration Law & 5 & 3 & 2 \\
\hline Labor Law & 19 & 19 & 2 \\
\hline Employment Law & 13 & 3 & 11 \\
\hline Discrimination Law & 6 & 2 & 1 \\
\hline Environmental Law & 15 & 4 & 6 \\
\hline Ethics & 8 & 8 & 11 \\
\hline Law \& Economics & 8 & 16 & 3 \\
\hline Law \& Society & 1 & 5 & 0 \\
\hline Law \& Psychology & $\mathbf{0}$ & 1 & 0 \\
\hline Legal History & 1 & 12 & 1 \\
\hline Race and the Law & 1 & 3 & 1 \\
\hline $\begin{array}{l}\text { Feminist Theory /Women } \\
\text { and the Law }\end{array}$ & 0 & 2 & 1 \\
\hline
\end{tabular}

There is an inherent simultaneity problem in asking such questions about course work. In order for a respondent to list a course as useful or stimulating, he or she would probably have had to have taken the course in law school. Moreover, although prior enrollment is not necessary for an affirmative answer on the third question, it would undoubtedly help. Thus we would expect that the responses received for each course would tend to vary based on a course's enrollment, with more widely-enrolled courses receiving more responses and courses with less enrollment or limited class sizes receiving fewer mentions. However, some classes have higher enrollments because the faculty deems them important to a legal career and require them, or the students anticipate, perhaps correctly, that these classes will be important to their careers. Thus, 
it seems plausible that the high enrollment classes truly are exceptionally stimulating and important. This simultaneity problem becomes more important as we move from the required first-year curriculum, which all alumni have taken, to the more advanced and specialized courses, which fewer students take. This problem in part accounts for the breadth of responses we observe regarding various classes, limiting the conclusions we can draw from the results.

Despite this limitation, we can still note some interesting trends in the courses our former students found valuable. Consistent with our expectations, the courses identified by our alumni as most valuable to their careers tend to be among the most highly-enrolled courses in the law school. The courses that were most frequently cited as useful include most of the first-year required curriculum. The course that was most often cited as useful was Contracts ( $n=98)$, followed by Civil Procedure $(n=72)$, Torts ( $n=68$ ), and Legal Research and Writing ( $n=65)$. These courses are all taught in the first semester of law school and provide students with their first introduction to the life and language of the law, as well as providing students with many of the core skills required in traditional legal careers. It might also be noted that, at least at Indiana, students spend more time in the top three courses than they do studying any other material in law school except Constitutional Law. After these first-year courses, the courses cited most often as being valuable to the careers of our alumni include courses such as Evidence $(n=64)$, Corporations $(n=44)$, and Tax $(n=38)$, which are typically taken by the majority of our students. Administrative Law $(n=48)$ also does well as a course that our alumni find useful, given its somewhat smaller enrollments.

The classes our graduates found most intellectually satisfying were Torts $(n=113)$ and Constitutional Law $(n=109)$. These classes present some of the most fundamental and fascinating legal principles in our American legal heritage. Other intellectually satisfying courses were Contracts ( $n=47)$, Criminal Law $(n=38)$, and Tax $(n=38)$. As anticipated, the number of responses in the "stimulating intellectually" category decreased among the advanced courses with smaller enrollments. Despite this fact, some courses with smaller enrollments did very well. For example, Law and Economics $(n=16)$ and Legal History $(n=12)$ were found to be stimulating intellectually by a substantial number of our alumni despite relatively small enrollments.

The final category, courses that our alumni think deserve expanded offerings, is perhaps the most interesting. Our graduates seem to be pleased with the level of training they received in the typical first-year classes. Although our alumni ranked these courses among the most valuable to their careers, their responses do not indicate any compelling need to add further offerings of these courses in the Law School curriculum. The Indiana Law faculty might take some satisfaction in the fact that our alumni ranked Legal Research and Writing $(n=62)$ as the subject with the most pressing need for expansion. Although our students tend to shy away from research and writing obligations in the curriculum, in recent years the faculty has aggressively moved to hire a full-time professional research and writing faculty and impose student writing requirements in all three years of our curriculum. The subjects that were next most frequently cited by our alumni for expansion include clinical opportunities ( $n=31)$, Tax $(n=24)$, and Corporations $(n=22)$. Like Legal Research and Writing, these classes represent some of most arduous and time-consuming classes that the school offers. However, these results suggest that, with the benefit of experience and hindsight, our alumni believe that these classes offer some real value in the 
development of career skills. Like parents telling their children to study hard, eat their vegetables, and brush their teeth, our alumni appear to suggest that a little pain for the law student during school will help cultivate a successful legal career in the long run.

\section{B. Law School Experience}

Expanding our focus to the larger law school experience, we next examine alumni satisfaction with the school experience and alumni participation in extracurricular activities. Tables 2 and 3 present the results for the classes of 1995-99 surveyed five years after graduation and the classes of 1985-89 surveyed fifteen years after graduation, respectively. Both tables examine whether our alumni found the law school satisfying intellectually, as career training, socially, and satisfying overall. These satisfaction variables represent the alumni responses on a seven-point scale ranging from "very satisfactory" $(+3)$ to "very unsatisfactory" $(-3)$. Accordingly, a positive mean response indicates that our alumni on average were satisfied with their experiences, and a negative mean response indicates that they were dissatisfied.

Although classroom experience plays a dominant role in a student's law school experience, student participation in extracurricular activities is also important. Tables 2 and 3 also present the percentage of alumni who report having participated in various law student activities including journal, moot court, student organizations, and clinical experiences. The means and percentages are reported for all observations and according to gender, race, ethnicity, and type of practice. To examine the respondents according to type of practice, their responses were separated into three groups, with one group including those who practice in large private practice firms (with greater than fifty lawyers employed nationwide) or as corporate counsel, a second group including those practicing in medium-sized firms (fifteen to fifty lawyers) or small private practices (less than fifteen lawyers), and a third group that includes those alumni who represent the government or work for public interest organizations.

Table 2. Law school experience-selected means and percentages for respondents to the five-year survey of the Indiana classes of 1995-99

\begin{tabular}{|c|c|c|c|c|c|c|c|c|c|c|}
\hline Variable & $\begin{array}{l}\text { All } \\
\text { obs. }\end{array}$ & Male & Female & $\begin{array}{l}\text { Non- } \\
\text { Black }\end{array}$ & Black & $\begin{array}{l}\text { Non- } \\
\text { Hisp. }\end{array}$ & Hisp. & $\begin{array}{l}\text { Lrg. } \\
\text { priv. } \\
\text { prac./ } \\
\text { corp. } \\
\text { coun. }\end{array}$ & $\begin{array}{l}\text { Med. } \\
\text { or } \\
\text { small } \\
\text { priv. } \\
\text { prac. }\end{array}$ & $\begin{array}{c}\text { Gov't/ public } \\
\text { int./ other }\end{array}$ \\
\hline $\begin{array}{l}\text { Satisfying } \\
\text { intellectually }\end{array}$ & 1.88 & $1.8 * *$ & $2.03^{* *}$ & 1.87 & 2.05 & 1.87 & 2.08 & $2.13^{* *}$ & $1.72^{*}$ & 1.69 \\
\hline $\begin{array}{l}\text { Satisfying as } \\
\text { career training }\end{array}$ & 0.55 & 0.53 & 0.59 & 0.53 & 0.91 & 0.54 & 0.92 & $0.90^{\text {** }}$ & $0.35^{*}$ & $0.28^{*}$ \\
\hline $\begin{array}{l}\text { Satisfying } \\
\text { socially }\end{array}$ & 1.05 & $0.94^{*}$ & $1.20^{*}$ & 1.08 & 0.68 & 1.05 & 1.00 & $1.41^{* *}$ & 1.19 & $0.61^{* *}$ \\
\hline $\begin{array}{l}\text { Satisfied with } \\
\text { law school } \\
\text { overall }\end{array}$ & 1.31 & $1.23^{*}$ & $1.43^{*}$ & 1.31 & 1.41 & 1.31 & 1.58 & $1.64^{* *}$ & 1.21 & $1.09 *$ \\
\hline $\begin{array}{l}\% \text { Participated } \\
\text { in journal }\end{array}$ & 48 & 48 & 49 & $50^{* *}$ & $18 * *$ & $49 * *$ & $25^{* *}$ & $72^{* *}$ & $34^{* *}$ & $37^{* *}$ \\
\hline $\begin{array}{l}\text { \% Participated } \\
\text { in moot court }\end{array}$ & 38 & 38 & 38 & $39^{*}$ & $23^{*}$ & 38 & 25 & 37 & $45^{* *}$ & 34 \\
\hline
\end{tabular}




\begin{tabular}{|c|c|c|c|c|c|c|c|c|c|c|}
\hline Variable & $\begin{array}{l}\text { All } \\
\text { obs. }\end{array}$ & Male & Female & $\begin{array}{l}\text { Non- } \\
\text { Black }\end{array}$ & Black & $\begin{array}{l}\text { Non- } \\
\text { Hisp. }\end{array}$ & Hisp. & $\begin{array}{l}\text { Lrg. } \\
\text { priv. } \\
\text { prac./ } \\
\text { corp. } \\
\text { coun. }\end{array}$ & $\begin{array}{l}\text { Med. } \\
\text { or } \\
\text { small } \\
\text { priv. } \\
\text { prac. }\end{array}$ & $\begin{array}{c}\text { Gov't/ public } \\
\text { int./ other }\end{array}$ \\
\hline $\begin{array}{l}\text { \% Participat } \\
\text { in student } \\
\text { group }\end{array}$ & 46 & $36 * *$ & $60^{* *}$ & $43^{* *}$ & $91 * *$ & 46 & 58 & 44 & 42 & $57 * *$ \\
\hline $\begin{array}{l}\% \text { Participat } \\
\text { in clinical } \\
\text { experience }\end{array}$ & 43 & $34^{* *}$ & $55^{* *}$ & 43 & 41 & $41^{* *}$ & $75^{* *}$ & $38 *$ & 46 & $54 * *$ \\
\hline Number & 349 & 198 & 142 & 315 & 22 & 328 & 12 & 100 & 100 & 67 \\
\hline
\end{tabular}

NOTE: * = significant at 0.1 level; $* *=$ significant at 0.05 level, one-tailed test.

Table 3. Law school experience-selected means and percentages for respondents to the fifteen-year survey of the Indiana classes of $1985-89$

\begin{tabular}{|c|c|c|c|c|c|c|c|c|}
\hline Variable & $\begin{array}{l}\text { All } \\
\text { obs. }\end{array}$ & Male & Female & $\begin{array}{c}\text { Non- } \\
\text { Black } \\
\text { Non- } \\
\text { Hispanic }\end{array}$ & $\begin{array}{l}\text { Black or } \\
\text { Hispanic }\end{array}$ & $\begin{array}{l}\text { Lrg. priv. } \\
\text { prac./corp. } \\
\text { coun. }\end{array}$ & $\begin{array}{l}\text { Med. or } \\
\text { small priv. } \\
\text { prac. }\end{array}$ & $\begin{array}{c}\text { Gov't/ public } \\
\text { int./ other }\end{array}$ \\
\hline $\begin{array}{l}\text { Satisfying } \\
\text { intellectually }\end{array}$ & 1.70 & 1.75 & 1.59 & 1.69 & 2.00 & $1.96^{* *}$ & $2.00^{* *}$ & $1.37^{* *}$ \\
\hline $\begin{array}{l}\text { Satisfying as } \\
\text { career training }\end{array}$ & 0.83 & 0.88 & 0.73 & 0.83 & 1.00 & $1.36^{* *}$ & 0.79 & 0.61 \\
\hline $\begin{array}{l}\text { Satisfying } \\
\text { socially }\end{array}$ & 1.00 & 0.98 & 1.03 & 0.99 & 1.0 & 1.02 & $1.32 * *$ & 0.92 \\
\hline $\begin{array}{l}\text { Satisfied with law } \\
\text { school overall }\end{array}$ & 1.33 & 1.37 & 1.25 & 1.33 & 1.50 & $1.72^{* *}$ & $1.52^{*}$ & 1.11 \\
\hline $\begin{array}{l}\% \text { participated in } \\
\text { journal }\end{array}$ & 21 & 21 & 22 & $22^{* *}$ & $0^{* *}$ & $32 * *$ & 16 & 16 \\
\hline $\begin{array}{l}\% \text { participated in } \\
\text { moot court }\end{array}$ & 18 & 19 & 15 & 17 & 20 & 21 & 18 & 24 \\
\hline $\begin{array}{l}\% \text { participated in } \\
\text { student group }\end{array}$ & 31 & 30 & 35 & $30^{* *}$ & $70^{* *}$ & 36 & $23^{* *}$ & 37 \\
\hline $\begin{array}{l}\% \text { participated in } \\
\text { clinical } \\
\text { experience }\end{array}$ & 26 & 25 & 27 & $24^{*}$ & $50^{*}$ & 27 & 27 & 32 \\
\hline Number & 243 & 169 & 74 & 230 & 10 & 53 & 62 & 38 \\
\hline
\end{tabular}

NOTE: * = significant at 0.1 level; $* *$ = significant at 0.05 level, one-tailed test.

Examining the results for the classes of 1995-99 presented in table 2, we see that our alumni are satisfied with their law school experiences. The respondents are generally the most satisfied with the Law School intellectually (1.88) and the least satisfied (though still satisfied) with the Law School as career training (0.55). Overall satisfaction with the law school (1.31) reflects an averaging of their satisfaction with school intellectually, as career preparation, and socially. Interestingly, among our alumni five years out of law school, women found the law school experience more satisfying than men. The women reported significantly more satisfaction with their law school experiences intellectually (2.03 versus 1.78$)$, socially (1.20 versus 0.94$)$, and 
overall (1.43 versus 1.23) than their male peers. In comparing means for the satisfaction variables a useful rule-of-thumb is that the standard error for the distribution variables is usually about 1 point, and so, assuming a normal distribution, near the mean, an increase of 0.2 points in satisfaction would represent jumping about $8 \%$ of the other respondents in the survey. Women also reported higher satisfaction with law school as career training, but that result was not statistically significant. Blacks and Hispanics reported greater intellectual satisfaction and career training satisfaction than non-Blacks and non-Hispanics, though those results are also not statistically significant.

Perhaps the most intriguing trends in our alumni's law school satisfaction are those associated with the type of practice they undertake. Those alumni who work in large private practice or as corporate counsel found law school significantly more satisfying in every category than their classmates who work in government or public interest (overall 1.64 versus 1.09 five years out and 1.72 versus 1.11 fifteen years out). They also found law school more satisfying than their classmates in medium-sized and small private practices ( 1.21 five years out and 1.52 fifteen years out). There are a number of possible explanations for this trend. First, it seems plausible that law schools are disproportionately focused on preparing students for large firm practice, so those alumni are more satisfied with their law school experiences. Second, it may be that large firms recruit disproportionate numbers of those who are more successful in law school and that success in law school is correlated with satisfaction with the law school experience. Third, it may be that satisfaction with the law school experience is correlated with alumni income or job satisfaction. As we will see in Part II, those who work in private practice earn considerably more income than those who work in government and public interest, and job satisfaction varies by type of practice. Finally, it may be that personal characteristics predispose a person to go into a certain type of practice, and those personal characteristics also determine whether he or she enjoys the law school experience. As will also be seen in Part II, alumni who reported they are more aggressive than average tend to go into large private practices while those who reported they are more compassionate than average tend to go into government and public interest work. These theories will be explored more in table 4, regression 1.

Participation in various student activities also varied by gender, race, ethnicity, and the type of practice the alum ultimately entered. Men and women exhibited similar participation rates in journal (48\% for the classes of $1995-99$ and $21 \%$ for the classes of 1985-99) and moot court (38\% for the classes of 1995-99 and $18 \%$ for the classes of 1985-99), but women in the classes of 1995-99 showed significantly higher involvement in student groups (60\% versus $36 \%$ ) and clinical experiences (55\% versus $34 \%$ ). Blacks and Hispanics reported lower participation in journals and moot court, but higher participation in student groups and clinics. Some of this variation is due to differences in opportunity. Although participation on two of Indiana's three studentedited journals is fairly open, participation on the staff of the Indiana Law Journal is determined by grades and a writing competition, and only a few students are invited to participate each year. Similarly, with respect to student groups, the law school has groups that are particularly aimed at the interests of women and minorities. Although the Women's Law Caucus (WLC) and the Black Law Student's Association (BLSA) add value to daily life for the entire law school community, the vast majority of their members belong to their respective gender or racial group, and there is no corresponding group organized in the interests of men. The effect of this fact on student participation in student groups is significant: if you disregard participation in 
the WLC or BLSA, the difference between the student group participation rates of men and women, and Blacks and non-Blacks significantly decreases or disappears. ${ }^{8}$ Finally, some of the variation in participation may be due to differences in the types of practice students want to enter. As will be seen in Part II, white men tend to go into private practice where journal participation is highly valued, while women, Blacks, and Hispanics tend disproportionately to go into government and public interest work where student organizing activity and clinical skills may be more valuable. Because there are only a limited number of hours in each day, alumni may have rationally chosen to undertake those activities that would be of most use to them in their future careers.

Table 3 presents analogous data to that presented in table 4, based upon the responses of Indiana alumni from the classes of 1985-89 surveyed fifteen years after graduation. Due to the low number of respondents in the 1985-89 classes who are Black or Hispanic, those observations have been combined into one category. The results for this sample show similar overall results to those for the classes of 1995-99, but there are some significant differences in the results among the subgroups. The average satisfaction levels for the 1985-89 classes as a whole are remarkably similar to those for the 1995-99 classes, with all groups reporting positive satisfaction values for each aspect of law school. Interestingly, unlike their younger counterparts, the female alumni for the classes of 1985-89 did not report any significant difference in satisfaction with law school from their male classmates. Except for social satisfaction, men in the 1985-89 classes reported slightly higher satisfaction values than women; however, none of these results are statistically significant. As with our 1995-99 alumni five years after law school, we find that our 1985-89 alumni practicing in large firms and as corporate counsel fifteen years after law school generally found their law school experiences more satisfying than those working in medium-sized private practice, small private practice, public interest, or government. The lone exceptions are that those working in medium and small private firms found their law school experiences more socially and intellectually satisfying than those in any other type of practice. Those working in government, public interest, or other types of practice found their law school experiences least satisfying intellectually.

The participation rates for the 1985-89 alumni surveyed fifteen years after graduation show similar, but more pronounced, trends than those for the 1995-99 alumni surveyed five years after graduation. The overall participation rates for journal, moot court, student groups, and clinics were higher in the five-year data than in the fifteen-year data, reflecting the increase in opportunities for student participation in extracurricular activities at the law school. ${ }^{9}$ As with satisfaction levels, male and

8. Examining the classes of 1995-99 and disregarding participation in the WLC and BLSA, the male participation rate in student groups is $33 \%$ while the female participation rate in students groups is $45 \%$, and the non-Black participation rate in student groups is $38 \%$ while the Black participation rate in student groups is $41 \%$. Examining the classes of $1985-99$ and disregarding participation in the WLC and the BLSA, the male participation rate in student groups is $28 \%$ while the female participation rate in students groups is also $28 \%$, and the nonBlack participation rate in student groups is $29 \%$ while the Black participation rate in students groups is $33 \%$.

9. Within the last fifteen years, the law school has added two new journals, the Indiana Journal of Global Legal Studies and the Federal Communications Law Journal, on which 
female participation rates did not differ significantly for the classes of 1985-89. Blacks and Hispanics showed significantly lower participation in journal than non-Blacks and non-Hispanics. In fact, none of the Black or Hispanic respondents in the classes of 1985-89 reported participating on a journal. Conversely, Blacks and Hispanics in the classes of 1985-89 participated much more heavily in student organizations and clinical opportunities than their non-Black and non-Hispanic counterparts.

Our analysis of means has shown that satisfaction with law school is associated with the type of practice in which the alum is engaged and the alum's gender. It is also reasonable to hypothesize that satisfaction with law school might depend on such factors as the alum's grades, participation in various law school activities, current income, job satisfaction, and success in his or her career. We also see that gender, race, and ethnicity may play a role in the type of practice the alum enters and the income he or she earns. In order to separate the effects of these factors on alumni satisfaction with the Law School, we need to use the statistical tool of linear regression analysis. ${ }^{10}$ Regression analysis estimates an equation explaining the dependent variable (such as overall satisfaction with the Law School) as a linear function of a collection of independent variables. The coefficients estimated for each independent variable can then be tested to determine whether they are statistically different from zero. In this way we can examine the impact of each independent variable on the dependent variable while holding the impact of the other independent variables constant.

In table 4, we estimate the alumni's reported overall satisfaction with law school as a function of the alumni's income, job satisfaction, law school GPA, type of practice, whether he or she made partner, gender, race, ethnicity, and whether he or she participated in various student activities. The equations are written with the default of a non-Black, non-Hispanic, non-Asian male who works in a supersized firm (greater than 150 attorneys), and so the coefficients for type of practice, gender, and ethnicity are expressed as differences from that default. Table 4, regression 1 presents the estimated coefficients for the classes of 1995-99 surveyed five years after graduation while regression 2 presents the estimated coefficients for the classes of 1985-89 surveyed fifteen years after graduation. The results of regression 1 suggest that satisfaction with law school is positively associated with good grades in law school (0.763). None of the other coefficients in regression 1 are statistically significant, although most have the expected signs, and moot court's positive coefficient and government and public interest's negative coefficients are close to statistically significant. The dummy variables for whether the respondent is working not as a partner in a given type of private practice play no role in regression 1 on the classes of 1995-99, since it had generally not been determined whether or not the respondents would make partner by the time of the survey five years after graduation. In regression 2, participation in journal $(0.932)$ and participation in moot court $(0.594)$ are both positively associated with law school satisfaction and both of these results are very significant. Also in regression 2, the few Asian alumni who answered the survey were significantly more satisfied with law school. The alum's current job satisfaction is also positively associated with law school satisfaction in regression 2, although this result is shy of statistical significance. Interestingly, working in a supersized firm in a position other than partner is positively associated with satisfaction with law school, although this result is just shy of statistical significance. It may be that many of the people who stay

students can participate in addition to the traditional Indiana Law Journal.

10. JAN KMENTA, ELEMENTS OF ECONOMETRICS 203-23 (Macmillan 2d ed. 1997) (1986). 
in these firms in non-partnership positions do so by choice and are happy with the more limited opportunities and responsibilities of such a position. Finally, those alumni who go into "other" types of work than legal practice are less satisfied with law school, and that result is just shy of statistical significance.

Table 4. Satisfaction with law school regressions

\begin{tabular}{|c|c|c|c|c|}
\hline \multirow{2}{*}{$\begin{array}{l}\text { Dependent variable } \\
\text { Satisfaction with law school }(-3 \text { to }+3) \\
\text { Independent variables }\end{array}$} & \multicolumn{2}{|c|}{$\begin{array}{l}\text { Regression 1: } \\
\text { Classes of 1995-99, } \\
\text { five years out }\end{array}$} & \multicolumn{2}{|c|}{$\begin{array}{l}\text { Regression 2: } \\
\text { Classes of } 1985-89, \\
\text { fifteen years out }\end{array}$} \\
\hline & Coefficient & $\begin{array}{l}\text { Signif. } \\
P>|t|\end{array}$ & Coefficient & $\begin{array}{l}\text { Signif. } \\
P>|t|\end{array}$ \\
\hline Income (in thousands of 2004 dollars) & .0011486 & .641 & .0011817 & .386 \\
\hline Overall job satisfaction $(-3$ to +3$)$ & .022128 & .768 & .1514016 & .157 \\
\hline Law school GPA (4 pt. scale) & $.7629135^{*}$ & .087 & .3771086 & .250 \\
\hline Participate in journal & .2364456 & .212 & $.9316981^{* *}$ & .000 \\
\hline Participate in moot court & .2325051 & .168 & $.5935785^{* *}$ & .010 \\
\hline Participate in student group & .1040386 & .548 & .058586 & .788 \\
\hline Participate in clinic & .0624182 & .696 & -.0296715 & .889 \\
\hline Not a partner, priv. prac. super & - & $\cdots$ & .6447832 & .112 \\
\hline Priv. practice large $(150>=\#$ Attys. $>50)$ & -.3371006 & .344 & .3826186 & .233 \\
\hline Not a partner, priv. prac. large & & ----- & & ---- \\
\hline Priv. practice med. $(50>=\#$ Attys. $>15)$ & -.4177527 & .185 & -.4633345 & .426 \\
\hline Not a partner, priv. prac. medium & -.--- & ---- & - & $\cdots$ \\
\hline Private practice small (15 >= \#Attys) & -.2043502 & .408 & .2981715 & .412 \\
\hline Not a partner, priv. prac. small & -..-- & - & .0056755 & .990 \\
\hline Corporate counsel & -.3720098 & .257 & .0312776 & .935 \\
\hline Government practice & -.4275016 & .152 & -.3152137 & .508 \\
\hline Public interest & -.6690028 & .164 & -.6699519 & .271 \\
\hline Other & -.0851244 & .746 & -.5787632 & .116 \\
\hline Female & .1645537 & .304 & -.0511895 & .822 \\
\hline Black & .3648897 & .373 & -.1098065 & .788 \\
\hline Asian & .0450212 & .884 & $1.080485^{* *}$ & .033 \\
\hline Hispanic & .227415 & .640 & .6914872 & .208 \\
\hline Constant & -1.356003 & .290 & -.3724215 & .725 \\
\hline Regression summary statistics & \multicolumn{2}{|c|}{$\begin{array}{l}\text { Number of obs. }=261 \\
F(18,242)=1.43 \\
\text { Prob. }>F=0.1161 \\
\text { R-squared }=0.0911 \\
\text { Root MSE }=1.2132\end{array}$} & \multicolumn{2}{|c|}{$\begin{array}{l}\text { Number of obs. }=138 \\
F(18,118)=-- \\
\text { Prob. }>F=- \\
\text { R-squared }=0.3568 \\
\text { Root MSE }=1.0427\end{array}$} \\
\hline
\end{tabular}

NOTE: $*$ = significant at 0.1 level; $* *=$ significant at 0.05 level.

On the whole, when our alumni look back on their time at Indiana University School of Law-Bloomington, they are generally satisfied with their experiences. Both our five- and fifteen- year alumni found their educational experiences generally satisfying. That such a result can be observed given the relative differences in rates of extra-curricular involvement, rates of part-time employment, and the rigors of the curriculum at Indiana University School of Law-Bloomington is a testament to the teaching ability of our faculty, the work ethic of our students, and the diversity of opportunities presented by the Law School community. 


\section{Paying for Law School}

We now turn our attention to the question of how our alumni paid for their educational experiences. With declining state support for education, students are being asked to cover an increasing share of the rising cost of their education. ${ }^{11}$ Certainly the decision to attend law school is in part financially motivated. ${ }^{12}$ How did our alumni finance the investment necessary to get the rewards of a legal education?

Tables 5 and 6 report the results for the classes of 1995-99, surveyed five years after graduation, and the classes of 1985-89, surveyed fifteen years after graduation, respectively. Respondents reported the source and percentage of financing supplied by each source. Respondents were also asked how many hours they were gainfully employed during their third year, their level of contractual debt accumulated as a result of law school, whether they had difficulty paying their debt, and whether they were concerned about debt repayment. The level of debt is reported in thousands of 2004 dollars, the variable on difficulty paying debt is a seven-point variable ranging from "no difficulty" $(-3)$ to "a great deal of difficulty" $(+3)$, and the variable on concern over paying debt is a seven-point variable from "not at all concerned" $(-3)$ to "extremely concerned" (+3). ${ }^{13}$ The results are broken down by gender, race, ethnicity, and type of practice.

Table 5. Paying for law school-selected means for respondents to the five-year survey of the Indiana classes of 1995-99

\begin{tabular}{|c|c|c|c|c|c|c|c|c|c|c|}
\hline Variable & $\begin{array}{l}\text { All } \\
\text { obs. }\end{array}$ & Male & Female & $\begin{array}{l}\text { Non- } \\
\text { Black }\end{array}$ & Black & $\begin{array}{l}\text { Non- } \\
\text { Hisp. }\end{array}$ & Hisp. & $\begin{array}{l}\text { Lrg. priv. } \\
\text { prac.J } \\
\text { corp. } \\
\text { coun. }\end{array}$ & $\begin{array}{l}\text { Med. or } \\
\text { small } \\
\text { priv. } \\
\text { prac. }\end{array}$ & $\begin{array}{c}\text { Gov't/ } \\
\text { public } \\
\text { int./ } \\
\text { other }\end{array}$ \\
\hline $\begin{array}{l}\text { \% Support } \\
\text { employment }\end{array}$ & 13 & 13 & 13 & 13 & 10 & $12^{*}$ & $20 *$ & 11 & 12 & 13 \\
\hline $\begin{array}{l}\text { \% Support IU/gov't } \\
\text { loans, grants, } \\
\text { scholarships }\end{array}$ & 34 & 34 & 33 & $31 * *$ & $66^{* *}$ & 34 & 31 & 33 & $30 *$ & 34 \\
\hline $\begin{array}{l}\% \text { Support private } \\
\text { loans }\end{array}$ & 23 & 22 & 25 & $24^{*}$ & $13^{*}$ & 23 & 35 & 23 & $28 *$ & 27 \\
\hline
\end{tabular}

11. In 2003, the American Bar Association (ABA) estimated that the average student graduates from law school with over $\$ 80,000$ in debt. ABA COMMISSION ON LOAN REPAYMENT \& FORGIVENESS, LifTING THE BURDEN: LAW SCHOOL DEBT AS A BARRIER TO PUBLIC SER VICE 8 (2003), available at http://www.abanet.org/legalservices/downloads/lrap/lrapfinalreport.pdf. In 1995 , the average debt burden for recent law school graduates was only $\$ 37,700$. Christopher T. Cunniffe, The Case for the Alternative Third-Year Program, 61 ALB. L. REv. 85, 100 (1997).

12. Students consider several factors when deciding to apply for law school. For an extensive discussion, see Ogloff et. al., supra note 7, at 81-82.

13. Unlike the satisfaction variables, where a positive response indicated relative satisfaction, the trouble and concern variables are inversely evaluated. Positive scores indicate a higher level or trouble or concern. For example, a response indicating a lot of trouble repaying a loan would have $a+3$ result. The negative mean values for these variables reported by our respondents indicate that our alumni have relatively little trouble and relatively small concern over their debt repayment. The more negative the observed mean, the less trouble or concern our respondents reported. 


\begin{tabular}{|c|c|c|c|c|c|c|c|c|c|c|}
\hline Variable & $\begin{array}{l}\text { All } \\
\text { obs. }\end{array}$ & Male & Female & $\begin{array}{l}\text { Non- } \\
\text { Black }\end{array}$ & Black & $\begin{array}{l}\text { Non- } \\
\text { Hisp. }\end{array}$ & Hisp. & $\begin{array}{l}\text { Lrg. priv. } \\
\text { prac. } \\
\text { corp. } \\
\text { coun. }\end{array}$ & $\begin{array}{l}\text { Med. or } \\
\text { small } \\
\text { priv. } \\
\text { prac. }\end{array}$ & $\begin{array}{l}\text { Gov't/ } \\
\text { public } \\
\text { int./ } \\
\text { other }\end{array}$ \\
\hline $\begin{array}{l}\text { S Support } \\
\text { spouse/partner (all } \\
\text { obs.) }\end{array}$ & 4.3 & 4.4 & 4.3 & 4.5 & 2.7 & $4.5^{* *}$ & $0 * *$ & $7.1^{* *}$ & 3.1 & $2.5^{*}$ \\
\hline $\begin{array}{l}\text { \% Support } \\
\text { spouse/partner } \\
\text { (married only) }\end{array}$ & 15 & 17 & 13 & 15 & 15 & $16^{* *}$ & $0^{* *}$ & $20^{*}$ & 15 & 12 \\
\hline $\begin{array}{l}\text { \% Support } \\
\text { parents/relatives } \\
\text { \% Support prior }\end{array}$ & 19 & 19 & 18 & $20 * *$ & $5.8 * *$ & $19 * *$ & $6 * *$ & 18 & 19 & 15 \\
\hline savings & 4.9 & 5.6 & 4.0 & $5.2^{* *}$ & $1.5^{* *}$ & 4.9 & 7.5 & 5.0 & $7.0^{*}$ & $2.5^{* *}$ \\
\hline $\begin{array}{l}\text { \% Support veteran } \\
\text { benefits }\end{array}$ & 0.5 & 0.5 & 0.6 & $0.5 * *$ & $0.0^{* *}$ & $0.5 * *$ & $0.0^{* *}$ & 0.4 & 0.8 & 0.7 \\
\hline \% Support other & 1.0 & 1.2 & 0.7 & $1.1^{*}$ & $0.2^{*}$ & $1.1^{* *}$ & $0.0^{* *}$ & $0.3^{*}$ & $0.1 * *$ & $4.3^{* *}$ \\
\hline $\begin{array}{l}\text { Hours of work third } \\
\text { year }\end{array}$ & 7.7 & $6.8 * *$ & $8.9 * *$ & $7.3 * *$ & $12.0^{* *}$ & 7.7 & 7.5 & $5.0^{* *}$ & 8.5 & $9.7^{* *}$ \\
\hline $\begin{array}{l}\text { Contractual debt from } \\
\text { law school (in } \\
\text { thousands of } 2004 \\
\text { dollars) }\end{array}$ & 49.3 & $47.0^{*}$ & $52.4^{*}$ & $47.6^{* *}$ & $69.6^{* *}$ & 49.3 & 44.1 & 49.8 & 50.4 & 53.7 \\
\hline $\begin{array}{l}\text { Difficulty paying } \\
\text { debt? }\end{array}$ & -0.82 & $-1.01 * *$ & $-0.54 * *$ & $-0.93 * *$ & *0.09** & -0.82 & -1.20 & $-1.66 * *$ & -0.70 & $0.23^{* *}$ \\
\hline Concern about debt? & -0.45 & $-0.70 * *$ & $-0.10^{* *}$ & -0.48 & -0.18 & -0.43 & -1.20 & -0.47 & $-0.90^{* *}$ & $-0.19^{*}$ \\
\hline Number & 342 & 199 & 143 & 316 & 20 & 257 & 10 & 100 & 81 & 67 \\
\hline
\end{tabular}

NOTE: ${ }^{*}=$ significant at 0.1 level; ${ }^{* *}=$ significant at 0.05 level, one-tailed test.

Table 6. Paying for law school—selected means for respondents to the five-year survey of the Indiana classes of 1985-89

\begin{tabular}{|c|c|c|c|c|c|c|c|c|}
\hline Variable & All obs. & Male & Female & $\begin{array}{l}\text { Non-Black } \\
\text { Non-Hisp. }\end{array}$ & $\begin{array}{c}\text { Black or } \\
\text { Hisp. }\end{array}$ & $\begin{array}{l}\text { Lrg. priv. } \\
\text { prac./corp. } \\
\text { coun. }\end{array}$ & $\begin{array}{l}\text { Med. or } \\
\text { small priv. } \\
\text { prac. }\end{array}$ & $\begin{array}{c}\text { Gov't/ } \\
\text { public } \\
\text { int./ } \\
\text { other }\end{array}$ \\
\hline $\begin{array}{l}\text { \% Support } \\
\text { employment }\end{array}$ & 23 & 23 & 22 & 23 & 30 & 24 & 24 & 19 \\
\hline $\begin{array}{l}\text { \% Support IU/gov't } \\
\text { loans, grants, } \\
\text { scholarships }\end{array}$ & 15 & 15 & 14 & $14^{* *}$ & $36 * *$ & 15 & 16 & 15 \\
\hline$\%$ Support private & & & & & & & & \\
\hline loans & 19 & 19 & 20 & 18 & 25 & 18 & 22 & 20 \\
\hline $\begin{array}{l}\text { \% Support } \\
\text { spouse/partner (all } \\
\text { obs.) }\end{array}$ & 7.5 & 6.7 & 9.4 & $7.8^{* *}$ & $2.5^{* *}$ & 9.8 & 5.9 & 10.1 \\
\hline $\begin{array}{l}\text { \% Support } \\
\text { spouse/partner } \\
\text { (married only) }\end{array}$ & 21 & 19 & 25 & 21 & 13 & 24 & 17 & 32 \\
\hline $\begin{array}{l}\text { \% Support } \\
\text { parents/relatives } \\
\% \text { Support prior }\end{array}$ & 26 & 26 & 26 & $27 * *$ & $2.5^{* *}$ & 23 & 22 & 26 \\
\hline savings & 6.5 & 7.3 & 4.9 & $6.8^{*}$ & $2.5^{*}$ & 7.5 & $9.6^{*}$ & 5.5 \\
\hline $\begin{array}{l}\text { \% Support veteran } \\
\text { benefits }\end{array}$ & 0.70 & 0.89 & 0.27 & 0.71 & 2.00 & 1.89 & $0.16^{*}$ & 1.1 \\
\hline \% Support other & 1.4 & 0.89 & 2.62 & $1.5 * *$ & $0.0^{* *}$ & $0.0^{* *}$ & $0.0^{* *}$ & 3.4 \\
\hline $\begin{array}{l}\text { Hours of work third } \\
\text { year }\end{array}$ & 10.5 & 10.5 & 10.6 & $10.2 * *$ & $18.4^{* *}$ & $8.4^{* *}$ & 10.8 & 11.3 \\
\hline
\end{tabular}




\begin{tabular}{|c|c|c|c|c|c|c|c|c|}
\hline Variable & All obs. & Male & Female & $\begin{array}{l}\text { Non-Black } \\
\text { Non-Hisp. }\end{array}$ & $\begin{array}{l}\text { Black or } \\
\text { Hisp. }\end{array}$ & $\begin{array}{l}\text { Lrg. priv. } \\
\text { prac./corp. } \\
\text { coun. }\end{array}$ & $\begin{array}{c}\text { Med. or } \\
\text { small priv. } \\
\text { prac. }\end{array}$ & $\begin{array}{c}\text { Gov't/ } \\
\text { public } \\
\text { int./ } \\
\text { other }\end{array}$ \\
\hline $\begin{array}{l}\text { Contractual debt } \\
\text { from law school } \\
\text { (thousands of } 2004 \\
\text { dollars) }\end{array}$ & 24.9 & 25.2 & 24.4 & $24.0^{* *}$ & $46.8^{* *}$ & 24.8 & 25.2 & $20.1^{*}$ \\
\hline $\begin{array}{l}\text { Difficulty paying } \\
\text { debt? }\end{array}$ & -2.07 & $-2.20^{* *}$ & $-1.71 * *$ & $-2.16^{* *}$ & $-0.30^{* *}$ & -2.08 & -2.18 & -1.88 \\
\hline Concern about debt? & -1.43 & $-1.57^{*}$ & $-1.06 *$ & -1.45 & -0.80 & -1.58 & -1.46 & -1.31 \\
\hline Number & 235 & 163 & 72 & 229 & 10 & 53 & 50 & 38 \\
\hline
\end{tabular}

NOTE: ${ }^{*}=$ significant at 0.1 level; ${ }^{* *}=$ significant at 0.05 level, one-tailed test.

Table 5 suggests that our alumni from the classes of 1995-99 have a diverse pool of financial resources. On average, our alumni from these classes funded their law school experiences through employment (13\%), law school or government loans, grants, and scholarships $(34 \%)$, private loans $(23 \%)$, parents $(19 \%)$, prior savings $(4.9 \%)$, veteran's benefits $(0.5 \%)$, and other means of financial support $(1 \%)$. The amount of financial support received from spouses is represented both as a mean percentage for all alumni $(4.3 \%)$ and as a mean percentage for only those alumni who were married during law school (15\%). Obviously, an unmarried student would not have had the opportunity to receive financial support from a spouse, while those who were married received substantial support.

Table 5 shows several interesting trends in students' law school funding strategies. First, gender plays no significant role in the percentage of financial support by source or relative percentage. On average, men and women utilized the same financial sources to the same extent. The same cannot be said across racial lines. Non-Blacks relied more on support from parents and other relatives, savings, and private loans while Blacks utilized university and government loans, grants, and scholarships in much higher proportions. Non-Black alumni, on average, funded $31 \%$ of their legal educations from university and government aid, $24 \%$ from private loans, and $20 \%$ from parental support while Blacks, on average, funded a full $66 \%$ of their educations with university and government support and only $13 \%$ from private loans and $5.8 \%$ from parental support. This difference perhaps reflects a difference in the availability of private resources between non-Black and Black law students. Hispanics relied more heavily on employment than non-Hispanics. $20 \%$ of Hispanic students' law school experiences were funded through employment. Non-Hispanics utilized employment to pay for only $12 \%$ of their law school experiences. Given this reliance on employment, Hispanics utilized spousal support, parental support, veteran's benefits, and other financial support significantly less than non-Hispanics. Hispanics in our survey relied on personal savings more heavily than non-Hispanics, but the result is not statistically significant.

Comparing financial resources across types of practice reveals little variability, with a few exceptions. Those alumni who work in a large private practice (greater than fifty lawyers) or as corporate counsel utilized spousal support significantly more than those who work in any other type of practice ( $20 \%$ versus $14 \%$ ). Could this be some sort of implicit deal between spouses, "you support my education and are rewarded with a large family income later"? Or perhaps guilt over the spouse's sacrifices compels the student to take a job with a large firm. Our alumni in medium or small private practice 
utilized private loans more heavily than other practice types, and they used government loans, grants, and scholarships less heavily than the other groups. Additionally, those in medium and small firms financed a higher proportion of their educations with prior savings while those who work in government or public interest relied less on prior savings. The alumni in medium and small firms seem to be the noble yeomen of the profession, working their way through school with the least amount of aid from other people.

Extracurricular employment is another means of financing law school. Table 5 reports the mean number of hours our respondents report working per week during their third year of law school. The results are presented regardless of motivation. That is, whether the students worked to pay for tuition, finance spring beak, gain practical experience, or secure a job does not figure into the analysis. Presumably, this variable not only represents the financial need of students, but also perhaps the need to be employed or simply the perceived value of employment itself. Significantly, women worked more in their third year (8.9 hours/week) than men (6.8 hours/week). Additionally, Blacks worked more in their third year (12 hours/week) than did nonBlacks (7.3 hours/week). Finally, those who work in large private practices or corporate counsel positions report working significantly less (5 hours/week) than average, while those who work in government or public interest report working significantly more ( 9.7 hours/week) in their third year of law school.

The bottom line for the classes of 1995-99 is that when they left the doors of Indiana University School of Law-Bloomington to begin their careers, on average they had acquired just under $\$ 50,000$ of contractual debt. Some students owed much more with a full $10 \%$ of our alumni reporting debts of $\$ 90,300$ or more and the most indebted respondent reporting a total debt of $\$ 153,000$. Debt varies significantly by gender and race. Women owed significantly more for their education than men $(\$ 52,400$ to $\$ 47,000)$. This $\$ 5400$ difference is somewhat surprising given that we have already found that women relied on the same sources as men, to approximately the same degrees. It may be that all of the insignificant ways in which women's law school funding varies from men's add up to a significant difference in the amount owed at the end of the education. It may also be that women, on average, spent $10 \%$ more to go to law school and thus ended up with $10 \%$ more debt even though they use resources in the same proportions as men. However, there is no evidence in our data that women spent more to go to law school. Similarly, we find that Blacks owed significantly more than non-Blacks for their education $(\$ 69,600$ to $\$ 47,600)$. Blacks relied much more heavily on university and government loans, grants, and scholarships than non-Blacks. Evidently this aid came more in the form of loans than grants and scholarships.

Given this level of debt upon completing law school, it is not surprising that at least some of our alumni reported some problems or concerns about repaying their debts. The good news is that, overall, our alumni report being closer to the "no difficulty" and "no concern" end of the spectrum in repaying their debts than they do to the "great deal of difficulty" and "extremely concerned" end of the spectrum expressed in our survey question. Recall that for these variables, the lower the reported mean, the less difficulty or concern our alumni had with respect to the examined problem, and negative means are on the lower half of the examined spectrum for responses. The only two groups 
who reported positive means, and thus greater problems and concerns in repaying their debts, were Black alumni and alumni who work for the government or public interest. ${ }^{14}$ As already discussed, Black alumni reported the highest level of debt, and, as will be seen later, government lawyers and public interest lawyers have lower incomes than their private practice counterparts. Predictably, attorneys in large private practice or corporate counsel positions reported the least difficulty and concern about repaying their debts. Also, perhaps because their average debts are larger and, as will be seen, their average incomes are smaller, women reported more problems and concerns about debt repayment than men, although both means were negative.

Table 6 presents analogous data regarding law school financing for the classes of 1985-89. Because the number of responses for Blacks and Hispanics was relatively low, their responses have been combined for the purposes of this table. Our graduates of the classes of 1985-89 funded their law school education in much different proportions than the 1995-98 alumni. These 1985-89 alumni relied more heavily on employment ( $23 \%$ to $13 \%$ ), spousal support ( $7.5 \%$ to $4.3 \%$ ), parental support ( $26 \%$ to $19 \%)$, and savings $(6.5 \%$ to $4.9 \%)$, and less heavily on university and government loans, grants, and scholarships (15\% to $34 \%)$ and private loans (19\% to $23 \%)$. Our graduates fifteen years out of law school reported working more hours during their third year of law school (10.5 hours/week) than our more recent graduates (7.7 hours/week).

However, many of the patterns among demographic groups that we observed in the responses from the classes of 1995-99 are also evident in the responses of the classes of 1985-89. Men and women used the same sources in about the same proportions. Women relied on spouses a bit more and prior savings a bit less, but the differences between men and women with respect to sources of funding are not significant. Blacks and Hispanics used university and government loans, grants, and scholarships at a much higher level than non-Blacks and non-Hispanics. Additionally, Blacks and Hispanics relied on parental support and prior savings significantly less than nonBlack-non-Hispanics. Blacks and Hispanics in the classes of 1985-89 reported working significantly more hours per week (18.4) than their non-Black-non-Hispanic classmates (10.2). Those alumni who worked in large firms reported working significantly fewer hours per week in their third year (8.4) than those alumni who worked in medium and small firms (10.8), as well as those who worked in government and public interest firms (11.3).

The 1985-89 graduates reported graduating with much less contractual debt than the more recent 1995-99 graduates. In 2004 dollars, the average reported debt at graduation for the classes of $1985-89$ was $\$ 24,900$, but for the classes of $1995-99$ the average reported debt was $\$ 49,300$. This difference undoubtedly reflects declining state support for education and rising tuition and other costs. Unlike our results for the classes of 1995-99, the women for the classes of 1985-89 reported less contractual debt than their male counterparts, although the difference is not significant. However, just as with the results for the classes of 1995-99, the minority graduates from the classes of 1985-89 reported substantially more contractual debt- $\$ 22,000$ more-than

14. These findings are consistent with David L. Chambers, Educational Debts and the Worsening Position of Small-Firm, Government, and Legal Services Lawyers, 39 J. LEGAL Educ. 709, 710, 719 (1989). 
their non-Black and non-Hispanic peers. Not surprisingly, with lower debt, the graduates of the classes of 1985-89 reported much less difficulty and concern in repaying their debts than the classes of 1995-99. All of the reported means for these variables are negative-sometimes over a full point more negative (less troubling) than the results for our more recent graduates. There is no significant difference in difficulty or concern with repaying debt among our 1985-89 graduates according to the type of practice the graduates entered. However, once again minority graduates, with the highest contractual debt, reported the most difficulty and concern in repaying their debts.

\section{Career Plans Before and After Law School}

We have now walked with our graduates through the classroom, through the law school experience as a whole, and through the problem of paying for law school. Before we consider the present status of our alumni, we make one last journey back to the law school experience. The data examined thus far have helped create a picture of how our alumni view their law school experiences, but it has only limited value in examining the overall effect a legal education has in shaping the professional choices of students. In this Part, we analyze whether and to what extent law school has changed our former students' career plans.

Tables 7 and 8 present data on alumni career plans both before and after law school. The alumni were asked to indicate which types of practice were in their "long-term career plans" both before and after law school. Table 7 presents those results with respect to the classes of 1995-99 surveyed five years after graduation, while table 8 presents comparable results for the classes of 1985-89 surveyed fifteen years after graduation. The results are broken down according to gender, race, ethnicity, and the type of practice the person actually went into. The values in the charts express the percentage of the total sample which gave that response. Because respondents could select a number of different plans, the sum of the percentages listed below in each column can exceed $100 \%$.

Table 7. Career plans both before and after law school-percentages of respondents to the five-year survey of the Indiana classes of 1995-99

\begin{tabular}{|c|c|c|c|c|c|c|c|c|c|c|}
\hline Variable & $\begin{array}{l}\text { All } \\
\text { obs. }\end{array}$ & Male & Female & $\begin{array}{l}\text { Non- } \\
\text { Black }\end{array}$ & Black & $\begin{array}{l}\text { Non- } \\
\text { Hisp. }\end{array}$ & Hisp. & $\begin{array}{l}\text { Lrg. priv } \\
\text { prac./ } \\
\text { corp. } \\
\text { coun. }\end{array}$ & $\begin{array}{l}\text { Med. or } \\
\text { small } \\
\text { priv. } \\
\text { prac. }\end{array}$ & $\begin{array}{l}\text { Gov't } \\
\text { public int./ } \\
\text { other }\end{array}$ \\
\hline $\begin{array}{l}\text { Before law school, } \\
\text { plan lrg. priv. prac. } \\
\text { or corp. coun. } \\
\text { After law school, } \\
\text { plan lrg. priv. prac. }\end{array}$ & 29 & $32^{*}$ & $25^{*}$ & 29 & 33 & 28 & 42 & $43 * *$ & $23 *$ & $17^{* *}$ \\
\hline $\begin{array}{l}\text { or corp. coun. } \\
\text { Before law school, } \\
\text { plan med. or small }\end{array}$ & 34 & 31 & 37 & 33 & 45 & 33 & 42 & $69 * *$ & $19 * *$ & $17^{* *}$ \\
\hline $\begin{array}{l}\text { priv. prac. } \\
\text { After law school, } \\
\text { plan med. or small }\end{array}$ & 15 & 16 & 14 & $16^{* *}$ & $0 * *$ & 15 & 17 & $9.1 * *$ & $29 * *$ & $9.1 * *$ \\
\hline $\begin{array}{l}\text { priv. prac. } \\
\text { Before law school, } \\
\text { plan gov't, public } \\
\text { int. or other }\end{array}$ & 30 & $26 * *$ & $35 * *$ & $28 * *$ & $0^{* *}$ & 27 & 25 & $9.2 * *$ & $58 * *$ & $9.2^{* *}$ \\
\hline
\end{tabular}




\begin{tabular}{|c|c|c|c|c|c|c|c|c|c|c|}
\hline Variable & $\begin{array}{l}\text { All } \\
\text { obs. }\end{array}$ & Male & Female & $\begin{array}{l}\text { Non- } \\
\text { Black }\end{array}$ & Black & $\begin{array}{l}\text { Non- } \\
\text { Hisp. }\end{array}$ & Hisp. & $\begin{array}{l}\text { Lrg. priv } \\
\text { prac.l } \\
\text { corp. } \\
\text { coun. }\end{array}$ & $\begin{array}{l}\text { Med. or } \\
\text { small } \\
\text { priv. } \\
\text { prac. }\end{array}$ & $\begin{array}{c}\text { Gov't } \\
\text { public int./ } \\
\text { other }\end{array}$ \\
\hline $\begin{array}{l}\text { After law school, } \\
\text { plan gov't, public } \\
\text { int., or other }\end{array}$ & 31 & $27 * *$ & $36 * *$ & 30 & 41 & 31 & 25 & $16 * *$ & $15^{* *}$ & $65^{* *}$ \\
\hline Number & 339 & 198 & 141 & 317 & 20 & 323 & 12 & 99 & 98 & 66 \\
\hline
\end{tabular}

NOTE: * = significant at 0.1 level; ** significant at 0.05 level, one-tailed test.

Table 8. Career plans before and after law school-percentages of respondents to the five-year survey of the Indiana classes of 1985-89

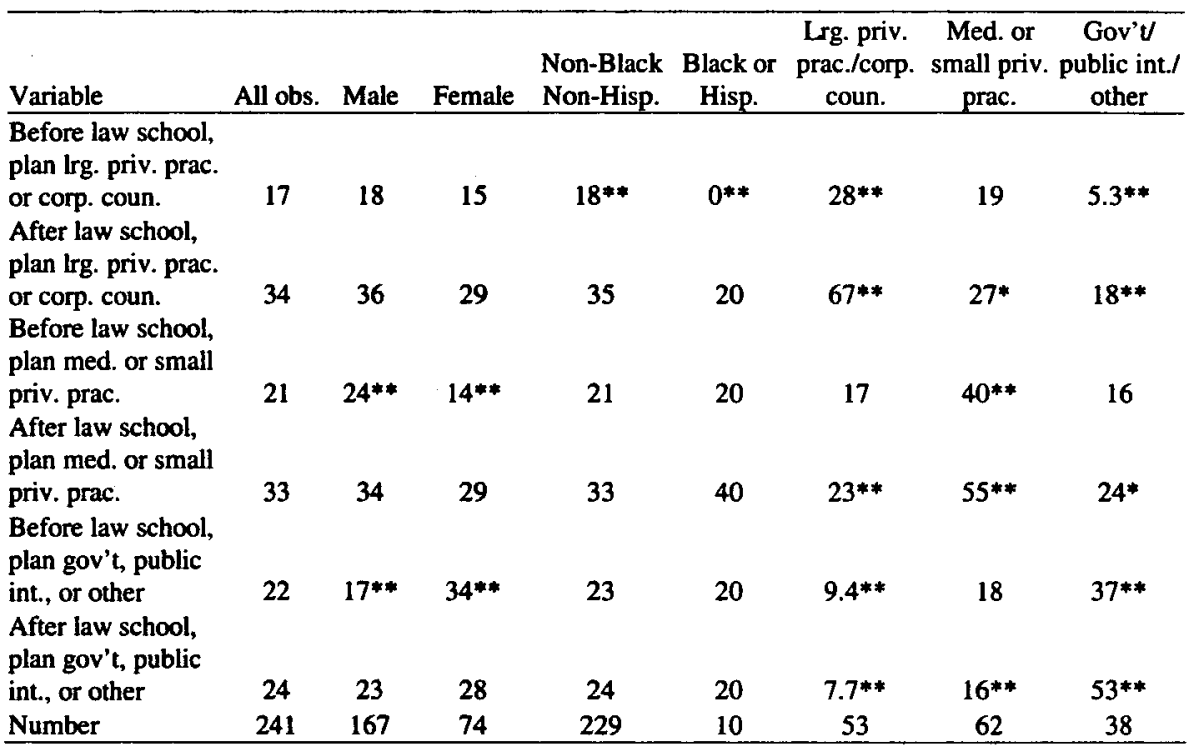

NOTE: * = significant at 0.1 level; ** = significant at 0.05 level, one-tailed test.

As represented in table 7, the classes of 1995-99 report a significant difference in career plans, and the impact of law school on those plans, according to gender. Significantly more men than women reported that, before law school, they planned to work in a large law firm or as corporate counsel (32\% versus $25 \%$ ). This trend reverses after law school, as women reported a higher likelihood of planning to work for a large law firm or as corporate counsel than men (37\% versus $31 \%$ ), although this result is not statistically significant. Both men and women report a greater incidence of planning to work in medium-sized or small private practices after law school. No similar increase is seen in plans to work for the government or public interest organizations after law school. Additionally, significantly more women than men planned on working for the government or a public interest organization before law school (35\% versus $26 \%$ ). That rate remains basically unchanged after the law school experience ( $36 \%$ versus $27 \%$ ). From these comparisons, it could be inferred that the law school experience encourages both men and women to work for private firms, although the effect is greater for women, especially with respect to large private firms 
and corporate counsel positions. This drift toward private practice in law school may be due to: (1) law school culture which treats private practice jobs as more valuable, ${ }^{\text {is }}$ (2) the useful transmission of information on the benefits of private practice during law school, (3) law students' experiences working in private practice during law school, or (4) students adjusting to the realities of the marketplace as to where good-paying jobs can be found.

Our Black and Hispanic alumni of the classes of 1995-99 report a more modest shift toward private practice. The largest shift is with respect to Black alumni plans to work in large private practices or corporate counsel positions. Our Black alumni report that, before law school, $33 \%$ of them planned to go into a large private practice or corporate counsel position, while after law school $45 \%$ of them entertained such plans. Interestingly, none of our Black alumni in the classes of 1995-99 planned to go into a medium-sized or small private practice, either before or after law school. It is also worth noting that our Hispanic alumni seem to lose interest in government and public interest jobs during law school, although the numbers of respondents are so small that the results are not significant.

In examining the results according to the respondent's current practice, table 7 suggests that, at least with the benefit of 20-20 hindsight, our alumni tend to go into the type of practice they planned to go into, especially according to their plans after law school. The percentage of respondents who work in a large firm and say they planned to work in a large firm, is significantly larger (43\% before law school and 69\% after law school) than those who work for a medium or small firm or in government practice or public interest and say they planned to go to a large firm (17\% and $23 \%$ ). Similarly, those who work in a medium or small firm are significantly more likely to say they had planned to enter such a practice ( $29 \%$ before law school and $58 \%$ after law school), and those who work for the government or public interest are also significantly more likely to say they planned to work in that practice ( $45 \%$ before law school and $65 \%$ after law school). Of those in large firms, an even higher percentage planned to work in a large firm after law school than had planned to do so before law school.

The data seem to expose an interesting affinity between large private practice and government or public interest work. Those who end up in medium to small private firms are almost equally likely to have planned, both before and after law school, to work in a large firm as to work in the government or a public interest organization. However, the earlier plans of those who end up in large firms or in government or public interest work do not suggest a similar division. Of those who end up in large firms and corporations, setting aside those who planned both before and after law school to practice in these sectors, a larger percentage planned both before and after law school to work in the government or public interest jobs than in medium or small practice firms. Conversely, of those who end up in government or public interest employment, a larger percentage planned, both before and after law school, to toil away in large firms or corporations than planned to work in small to medium firms.

15. For a comprehensive study on the question of the impact of law school on entry into the legal profession, see Lewis Kornhauser \& Richard Revesz, Legal Education and Entry Into the Legal Profession: The Role of Race, Gender and Educational Debt, 70 N.Y.U. L. REV. 829 (1995). 
Perhaps these students were anticipating the revolving door that sometimes moves lawyers from large firms to the government and back.

Table 8 presents the plans for the classes of 1985-89 before and after law school, surveyed fifteen years after graduation. Once again, the most notable differences occur across genders. Both men and women in the classes of 1985-89 changed their plans during the course of law school, as a higher percentage of students planned on working for a large firm or corporate counsel after law school. Before law school, more men planned on working in medium or small private firms than women ( $24 \%$ versus $14 \%$ ), and more women planned on government or public interest firms than men (34\% versus $17 \%$ ). After law school, these differences had largely dissipated. Men and women planned on moving into all forms of practice in relatively even proportions. Whether it is socialization, the provision of information, or the dictates of the market, the experience of legal education seems to have a regulating effect on people's expressed job intentions in favor of private practice.

Recall that minorities in the classes of 1995-99 seemed to differ in two ways from their majority classmates. First, we observed an increase in the number of Blacks who planned to work for large firms or corporate counsel after law school, and a decrease in the number of Hispanics who planned to work for government. Neither of these trends is evident in the survey results from the classes of 1985-89. Once again, due to a low sample size, we had to combine the responses from our Black and Hispanic alumni for the classes of 1985-89. For these senior alumni, we see no large difference in the way law school affects the plans of our minority alumni compared to the non-Black and non-Hispanic alumni. There is a difference, however, in the initial plans of minority students. No Blacks or Hispanics in this sample reported that, before law school, they planned to work for a large firm, which is significantly different from the pre-law school plans of non-Black and non-Hispanic students (18\%). There is an increase in the percentage of Blacks and Hispanics who plan on working in a large firm after law school, but it is not very different from the corresponding increase among non-Black and non-Hispanics. Because our sample of Black or Hispanic alumni from the classes of $1985-89$ is so small ( $n=10$ ), the $20 \%$ increase observed in table 8 represents only two respondents changing their plans over the course of law school. It would be difficult to use this data to support a notion that the trend holds for all our minority alumni of that time period.

Like their more recent academic siblings in table 7, the majority of our alumni for the classes of 1985-89 report having planned, at least after law school, to work in the field in which they ended up working. A relatively large percentage of our alumni who end up working in large firms or corporations planned on working in large firms or corporations before law school and an even larger percentage planned on working in large firms or corporations after graduating from law school. Once again, that trend repeats itself for those who end up in small and medium firms and those who end up in government and public interest work. There is a significant connection between students who plan on working in a particular sector before law school and those who eventually work in that sector. There is an even stronger correlation between students who plan on working in a particular sector after law school and those who eventually engage in that type of practice. 


\section{II. “AIN'T God GoOD to INDIANA?": ${ }^{16}$ THE CAREERS OF INDIANA LAW AlUMNI}

We have walked with our alumni through the classroom and out the door of the law school. Once our students leave the nurturing environs of the law school, who do they become? In this Part we continue our walk with our alumni, evaluating personal characteristics that may predispose our alumni to certain career choices, the career opportunities our alumni pursued, and our graduates' income and satisfaction in their chosen path. Lastly, we use linear regression to unearth the relative effects of certain characteristics on income and job satisfaction in an attempt to make sense of the cold harsh world outside "old I.U."

\section{A. Personal Characteristics that Might Affect a Legal Career or Be Affected by that Career}

Undoubtedly, personal characteristics affect a person's health, relationships, family experience, educational experience, and inevitably his or her career as well. Certainly some characteristics may predispose a person to a particular career path. The next question we will examine is who are our alumni? That is, what types of characteristics make Indiana Law graduates the people they are? The types of personal and family characteristics that might contribute to career choices are considered in this Part.

It is often assumed that lawyers have certain characteristics that predispose them to the profession. Fairly or unfairly, aggressiveness may be one of the characteristics most often used in describing members of the legal profession. ${ }^{17}$ However, lawyers also negotiate a lot of deals and, at least in certain positions, are responsible for enforcing various public policies. Accordingly, a more cooperative and compassionate nature may predispose a person to success in certain types of practice. Moreover, in their career choices some people may be motivated primarily by a desire to make money, while others may be motivated more by a desire to make an impact on society. These differing motivations will undoubtedly have an impact on the types of legal practice alumni choose to go into, as well as the amount of income they earn. Likewise, characteristics of a person's family, including marital status, parental status, and personal goals related to their family will also affect the working life of that person. All of these attributes have profound effects on the choices of our graduates as they enter the workforce and progress through the course of their legal careers.

Tables 9 and 10 examine the personal and family characteristics of the members of the classes of 1995-99, surveyed five years after graduation, and the members of the

16. William Herschell, Ain't God Good to Indiana?, available at http://members.aol.com/ sycophant4/Indiana.htm (last visited Mar. 4, 2006). The poem is probably the best-known work of Herschell, a journalist who was a reporter at the Indianapolis News for 37 years. The text of the poem is also inscribed on a plaque in the rotunda of the Indiana Statehouse.

17. See Susan Daicoff, Asking Leopards to Change Their Spots: Should Lawyers Change? A Critique of Solutions to Problems with Professionalism by Reference to Empirically-Derived Attorney Personality Attributes, 11 GeO. J. LEGAL ETHICS 547 (1998) (arguing that these characteristics found naturally in lawyers have led to the demise of the profession). Without taking such a hard normative stance on such a claim, we note only that the aggressive and competitive nature of lawyers and students of law also help increase the quality of their work product and provide valuable services to their clients. 
classes of $1985-89$, surveyed fifteen years after graduation. The respondents evaluated their desire for money, desire for social impact, aggression, and compassion "relative to other lawyers their age" on a seven-point scale from "much less than most" $(-3)$ to "much more than most" $(+3)$. Variables describing our alum's status as married, not working because of child care responsibilities, and having a spouse with an intense job are shown as a percentage value of the total. An intense job, for the purposes of this evaluation, indicates that the spouse is either a professional (doctor, lawyer, nurse, etc.) or a business manager. The figure for the number of children living in the home expresses the average number of children our alumni reported as currently living with them. The income variables are expressed in thousands of 2004 dollars. The final variable, "income as a percent of total household income," is the percentage of the household income earned by the alum-respondent. All of the variables are broken down according to gender, race, and ethnicity. Again, data for Blacks and Hispanics are combined for the fifteen-year survey due to low numbers.

Table 9. Selected means of personal and family characteristics, five-year survey, Indiana classes 1995-99 (income in thousands of $\mathbf{2 0 0 4}$ dollars)

\begin{tabular}{|c|c|c|c|c|c|c|c|}
\hline Variable & $\begin{array}{c}\text { All } \\
\text { observations }\end{array}$ & Men & Women & Non-Black & Black & $\begin{array}{c}\text { Non- } \\
\text { Hispanic }\end{array}$ & Hispanic \\
\hline Desire for money & -0.35 & $-0.03^{* *}$ & $-0.78 * *$ & -0.34 & -0.45 & -0.36 & 0.08 \\
\hline $\begin{array}{l}\text { Desire for social } \\
\text { impact }\end{array}$ & 0.47 & $0.22 * *$ & $0.82 * *$ & $0.43^{*}$ & $1.09 *$ & $0.44^{*}$ & $1.33^{*}$ \\
\hline Aggression & 0.16 & $0.25^{*}$ & $0.05^{*}$ & $0.10^{*}$ & $0.82 *$ & $0.11^{* *}$ & $0.92 * *$ \\
\hline Compassion & 1.19 & $0.90^{* *}$ & $1.59 * *$ & 1.19 & 1.36 & $1.17^{* *}$ & $1.92^{* *}$ \\
\hline$\%$ Married now & 65 & 64 & 67 & $67 *$ & $50^{*}$ & 66 & 50 \\
\hline $\begin{array}{l}\text { Number of kids in the } \\
\text { home }\end{array}$ & 0.63 & 0.67 & 0.57 & 0.63 & 0.50 & 0.63 & 0.58 \\
\hline $\begin{array}{l}\text { \% Ever part-time or } \\
\text { not work due to } \\
\text { childcare }\end{array}$ & 11 & $1 * *$ & $24 * *$ & 11 & 9 & 11 & 8 \\
\hline $\begin{array}{l}\% \text { Spouse is a } \\
\text { homemaker }\end{array}$ & 9.9 & 10.3 & 9.4 & $10.5^{* *}$ & $0 * *$ & $10^{* *}$ & $0^{* *}$ \\
\hline $\begin{array}{l}\text { \% Spouse has intense } \\
\text { job }\end{array}$ & 63 & $54 * *$ & $74 * *$ & $61 *$ & $82 *$ & 63 & 50 \\
\hline $\begin{array}{l}\text { Spouse income (in } \\
\text { thousands of } 2004 \\
\text { dollars) }\end{array}$ & 57.1 & $43.1 * *$ & $75.8 * *$ & 56.2 & 76.8 & 57.1 & 63.2 \\
\hline $\begin{array}{l}\text { Total household } \\
\text { income (in thousands } \\
\text { of } 2004 \text { dollars) }\end{array}$ & 144.4 & 142.3 & 147.3 & 146.2 & 125.1 & 145.0 & 141.5 \\
\hline $\begin{array}{l}\text { Income as \% of total } \\
\text { household income }\end{array}$ & 67 & $71 * *$ & $60 * *$ & 67 & 67 & 66 & 77 \\
\hline Number & 340 & 197 & 143 & 316 & 22 & 326 & 12 \\
\hline
\end{tabular}

NOTE: * = significant at 0.1 level; $* *=$ significant at 0.05 level, one-tailed test. 
Table 10. Selected means of personal and family characteristics, fifteen-year survey, Indiana classes $1985-89$ (income in thousands of 2004 dollars)

\begin{tabular}{|c|c|c|c|c|c|}
\hline Variable & $\begin{array}{c}\text { All } \\
\text { observations }\end{array}$ & Men & Women & $\begin{array}{c}\text { Non-Black } \\
\text { Non-Hispanic }\end{array}$ & $\begin{array}{l}\text { Black or } \\
\text { Hispanic }\end{array}$ \\
\hline Desire for money & -0.65 & $-0.39 * *$ & $-1.27 * *$ & -0.67 & -0.20 \\
\hline Desire for social impact & 0.73 & $0.65^{*}$ & $0.93^{*}$ & $0.69 *$ & $1.40^{*}$ \\
\hline Aggression & 0.23 & $0.41^{* *}$ & $-0.19 * *$ & 0.20 & 0.80 \\
\hline Compassion & 1.43 & $1.36^{*}$ & $1.60^{*}$ & $1.41^{*}$ & $2.00^{*}$ \\
\hline$\%$ Married now & 82 & $86^{* *}$ & $74 * *$ & 83 & 70 \\
\hline Number of kids in the home & 1.81 & 1.86 & 1.70 & 1.82 & 1.60 \\
\hline $\begin{array}{l}\text { \% Ever part-time or not work } \\
\text { due to childcare }\end{array}$ & 13 & $2^{* * *}$ & $40^{* *}$ & 13 & 20 \\
\hline$\%$ Spouse is a homemaker & 12 & 13 & 9 & 12 & 14 \\
\hline \% Spouse has intense job & 46 & $38^{* *}$ & $67 * *$ & $45^{*}$ & $71^{*}$ \\
\hline $\begin{array}{l}\text { Spouse income (in thousands } \\
\text { of } 2004 \text { dollars) }\end{array}$ & 53.5 & $31.0^{* *}$ & $121.2^{* *}$ & 52.6 & 76.9 \\
\hline $\begin{array}{l}\text { Total household income (in } \\
\text { thousands of } 2004 \text { dollars) }\end{array}$ & 219.1 & 225.4 & 202.6 & 219.2 & 205.6 \\
\hline $\begin{array}{l}\text { Income as \% of total } \\
\text { household income }\end{array}$ & 74 & $80^{* *}$ & $56^{* *}$ & $75^{*}$ & $55^{*}$ \\
\hline Number & 240 & 166 & 74 & 224 & 10 \\
\hline
\end{tabular}

NOTE: * = significant at 0.1 level; $* *$ = significant at 0.05 level, one-tailed test.

Tables 9 and 10 show very similar patterns in personal characteristics for the classes of 1995-99 and 1985-89. Significantly, men admit to a higher desire for money $(-0.03$ and -0.39$)$ than women $(-0.78$ and -1.27$)$, although the negative mean of all respondents indicates that no particular group considers their own desire for money to be stronger than that of other lawyers. On the other hand, women, Blacks, and Hispanics demonstrate a higher desire for social impact ( 0.82 to 1.40$)$ than men and the non-Black and non-Hispanic samples $(0.22$ to 0.69$)$. Also, in both samples men rate themselves as more aggressive, while women consider themselves more compassionate. Blacks and Hispanics consider themselves both more aggressive and more compassionate in both the five- and fifteen-year surveys, although the results are not always significant. Of course, the evaluations given by the respondents regarding their own personal characteristics could reflect the respondents' beliefs about social expectations. For example, men may have indicated that they desire money more and are less compassionate because that is what they believe society expects them to care about. The consistently negative numbers for socially negative characteristics such as "desire for money," and positive numbers for socially positive characteristics such as "compassion" suggest a certain amount of reporting based on social expectations. Biological differences between men and women may also play a role. ${ }^{18}$ The survey

18. According to evolutionary theorists, sexual selection, both intrasexual and intersexual, promotes different traits in men and women. RICHARD C. FRANCIS, WHY MEN WON'T ASK FOR Directions, The SEDUCTIONS OF SOCIOBIOLOGY 106 (2004). Intrasexual selection involves competition between the same sex for mates of the opposite sex, and intersexual selection 
responses are also difficult to interpret because they depend on both the person's assessment of his or her own personal characteristics, and the person's assessment of other people. Nevertheless, the survey results suggest some real differences in personal characteristics across gender, race, and ethnicity that may help explain some career choices.

Both the five-year survey and the fifteen-year survey also show consistent variations in family characteristics, particularly across gender. Men are significantly more likely than women to be married fifteen years after law school ( $86 \%$ versus $74 \%$ ), although both men and women live with roughly the same number of children (1.81 and 1.86, respectively). Women are much more likely to marry a spouse with an intense job (67\% versus $38 \%$ fifteen years out) and the women's spouses earn much more than the men's spouses ( $\$ 121,200$ versus $\$ 31,000$ fifteen years out!). Perhaps the greatest gender difference occurs in the percent of respondents who report ever working part time or not working to do child care. Fully $24 \%$ of the female respondents for the classes of 1995-99 and 40\% of the female respondents from the classes of 1985-89 indicate that at some point they have left the paid labor market to do child care, while only $1 \%$ of male respondents from the classes of $1995-99$ and $2 \%$ of male respondents from the classes of 1985-89 report having done so! There is some evidence that Black and Hispanic alumni are more likely to have a spouse with an intense job, although the results are not always significant.

All of these family characteristics suggest that our alumni tend to divide family responsibilities in a somewhat traditional manner. Although there are many exceptions, male alumni are more likely to be the family breadwinner, providing the majority of the household income with a spouse who works part time in the paid labor market. ${ }^{19}$ Female alumni are more likely to be married to a spouse with an intense job, provide a lower percentage of household income, and take time away from their careers to provide child care. These facts undoubtedly impact the future career paths of our alumni.

involves making one attractive for the opposite sex. If there are such forces at work, men may become more assertive in order to appear attractive to the opposite sex or fend off other wouldbe suitors. Men would be expected to seek money if that will be important to potential mates. Women in turn become more compassionate for the same subconscious reproductive reasons. In this manner, our small sample of alumni may simply be evidence of deeper mating strategies. Francis is quick to point out that some differences between genders occur for no reason at all. "It is only when we can demonstrate such sexual selection that we can equate male navigational skills to deer antlers and explain why men won't ask for directions." Id. at 160 . He then argues that male math aptitude is not likely to be a result of evolutionary forces. The concepts of gender differences are highly debated in the field of evolutionary biology. Three of the authors endorse no view on the subject; we mention the view as a hypothesis for the results we observe. It should, however, be noted that the average number of children produced by the author who endorses this view (3) is higher than the average number of children produced by the authors who don't necessarily endorse this view (1.3).

19. This finding is consistent with other empirical research in the subject. David L. Chambers, Accommodation and Satisfaction: Women and Men Lawyers and the Balance of Work and Family, 14 LAW \& SOC. INQUIRY 251, 278-79 (1989). 


\section{B. Type of Practice}

Now that we know a bit about who our alumni are, we turn to one of the questions posed in the beginning of this article: What do our alumni do? In this Part we examine their legal careers. We will first note the types of practice our alumni undertake. Comparing across gender, race, and ethnicity, we will attempt to describe some of our observations in the context of the complex of the varying personality traits observed above, and of competing demands of jobs and families.

Tables 11 and 12 present the type of practice our alumni indicate that they have undertaken; table 11 for the classes of 1995-99 surveyed five years after law school, and table 12 for the classes of 1985-89 surveyed fifteen years after law school. Once again, the responses for our Black and Hispanic alumni are combined in the fifteenyear survey due to low numbers. The following descriptions apply to tables 11 and 12: a "super" private practice firm is one that employs more than 150 attorneys nationwide; a "large" private practice firm is one that employs from 50 to 150 attorneys nationwide; a "medium" private practice firm is one that employs from 15 to 50 lawyers nationwide; and a "small" private practice firm employs fewer than 15 lawyers nationwide. Other types of practices examined are those of alumni who practice as corporate counsel or in government or public interest organizations. Alumni who indicate that they do not fit into one of these categories or are not currently practicing law are categorized as "other." The careers of these "other" alumni are explored in tables 14 and 15. The results in both tables 11 and 12 are broken down by gender, race, and ethnicity.

Table 11. Percent of respondents to the five-year survey of Indiana classes 1995-99 in each type of practice

\begin{tabular}{|c|c|c|c|c|c|c|c|}
\hline Variable & $\begin{array}{c}\text { All } \\
\text { observations }\end{array}$ & Men & Women & Non-Black & Black & $\begin{array}{c}\text { Non- } \\
\text { Hispanic }\end{array}$ & Hispanic \\
\hline $\begin{array}{l}\text { Super priv. prac. } \\
\text { (\# attys. >150) }\end{array}$ & 14.3 & 14.2 & 14.5 & $15.1^{* *}$ & $4.8 * *$ & 14.2 & 18.2 \\
\hline $\begin{array}{l}\text { Large priv. prac. } \\
(150>=\# \text { attys. }>50)\end{array}$ & 7.6 & 7.4 & 8.0 & $8.2^{* *}$ & $0.0 * *$ & $8.0 * *$ & $0.0^{* *}$ \\
\hline $\begin{array}{l}\text { Medium priv. prac. } \\
(50>=\# \text { attys. > 15) }\end{array}$ & 11.0 & $13.2^{*}$ & $8.0^{*}$ & $11.5^{*}$ & $4.8^{*}$ & $11.5^{* *}$ & $0.0^{* *}$ \\
\hline $\begin{array}{l}\text { Small priv. prac. } \\
(15>=\text { \# attys.) }\end{array}$ & 20.1 & $24.2 * *$ & $14.5^{* *}$ & $20.7 * *$ & $4.8^{* *}$ & 19.1 & 36.4 \\
\hline Corporate counsel & 8.5 & 7.4 & 10.1 & $7.2^{*}$ & $23.8^{*}$ & 8.3 & 9.1 \\
\hline Government & 15.3 & $12.6^{*}$ & $18.8^{*}$ & 14.8 & 23.8 & 15.2 & 18.2 \\
\hline Public interest & 4.3 & 3.6 & 5.1 & 3.9 & 9.5 & 4.1 & 9.1 \\
\hline Other & 18.9 & 17.4 & 21 & 18.6 & 28.5 & 19.6 & 9 \\
\hline Number & 328 & 190 & 138 & 304 & 21 & 314 & 11 \\
\hline
\end{tabular}

NOTE: * = significant at 0.1 level; ${ }^{* *}=$ significant at 0.05 level, one-tailed test. 
Table 12. Percent of respondents to the fifteen-year survey of Indiana classes $1985-89$ in each type of practice

\begin{tabular}{lccccc}
\hline Variable & All observations & Men & Women & $\begin{array}{c}\text { Non-Black Non- } \\
\text { Hispanic }\end{array}$ & $\begin{array}{c}\text { Black or } \\
\text { Hispanic }\end{array}$ \\
\hline $\begin{array}{l}\text { Super-size priv. prac. } \\
\text { (\# attys. >150) }\end{array}$ & 7.1 & 8.0 & 4.8 & 7.0 & 11.1 \\
$\begin{array}{l}\text { Large priv. prac. } \\
(150>=\text { \# attys. }>50)\end{array}$ & 6.3 & $8.0^{* *}$ & $1.6^{* *}$ & $6.6^{* *}$ & $0.0^{* *}$ \\
$\begin{array}{l}\text { Medium priv. prac. } \\
\text { (50>= \# attys. }>15)\end{array}$ & 4.5 & 4.9 & 3.2 & $4.7^{* *}$ & $0.0^{* *}$ \\
$\begin{array}{l}\text { Small priv. prac. } \\
\text { (15>= \# attys.) }\end{array}$ & 23.2 & $25.9 * *$ & $16.1^{* *}$ & 23.5 & 11.1 \\
Corporate counsel & 10.3 & 8.6 & 14.5 & $10.8^{* *}$ & $0.0^{* *}$ \\
Government & 13.4 & 12.3 & 16.1 & 13.1 & 22.2 \\
Public interest & 3.6 & 2.5 & 6.5 & 3.3 & 11.1 \\
Other & 31.6 & 29.8 & 37.2 & 31 & 44.5 \\
Number & 224 & 162 & 62 & 215 & 9 \\
\hline
\end{tabular}

NOTE: * = significant at 0.1 level; ${ }^{* *}=$ significant at 0.05 level, one-tailed test.

Examining these results, we see that the plurality of our alumni go into private practice ( $53 \%$ five years out, $41 \%$ fifteen years out) with many graduates working in large or super firms (22\% five years out, $13.4 \%$ fifteen years out). After private practice, the next largest category is, surprisingly, "other" (18.9\% five years out, $31.6 \%$ fifteen years out), followed by government ( $15.3 \%$ five years out, $13.4 \%$ fifteen years out); corporate counsel ( $8.5 \%$ five years out, $10.3 \%$ fifteen years out); and public interest ( $4.3 \%$ five years out, $3.6 \%$ fifteen years out). Moreover, there is evidence in the data that our female and Black alumni either choose, or end up in, the "other" category in greater proportion. ${ }^{20}$ As previously mentioned, the "other" category consists of alumni whose jobs do not fit into the practice categories presented. As will be seen later, the alumni in the "other" category are primarily judges, public officials, government employees, educators, and business managers. The large number of alumni in the "other" category is a testament to the many and varied talents of our alumni and the general educational value of a legal education. Our graduates have a variety of talents and interests, and legal education is good training for many jobs outside the traditional practice of law. Large numbers of alumni appear to be utilizing these talents and interests by pursuing opportunities outside the traditional legal paradigm.

The results from the classes of 1995-99 indicate that women have done very well in their placement across the profession. Five years after law school, our female alumni are going into every type of practice, except medium and small private firms, at a faster rate than men. Our discussions with female alumni in focus groups that reviewed these results suggest that women are less likely to go into small and medium private practices because they perceive such practices as having less ability to accommodate part-time work and family commitments. Moreover, demand for diverse legal teams from large

20. For prior empirical studies on lawyers who choose not to practice law, see Fiona M. Kay, Flight From Law: A Competing Risks Model of Departures From Law Firms, 31 L. \& SoC'Y REV. 301 (1997). See also Joan Brockman, Leaving the Practice of Law: The Wherefores and Whys, 32 ALTA. L. REV. 116 (1994). 
firm clients, corporations, and government probably also plays a role. ${ }^{21}$ Most notably, women are going into super and large firms at a faster rate than men, although this difference is not statistically significant. Although women in the classes of 1995-99 are going into large private practices at a faster rate than men, the results from the classes of 1985-89 suggest that among the senior alumni, women are underrepresented in private practice and overrepresented in corporate counsel, government, and public interest practice. The reasons for these differences between the placement of women in the classes of 1995-99 and 1985-89 might be "generational" or "life-cycle." Women in the more recent classes may be generationally different in that they have greater opportunities and/or preferences for large firm private practice than women in the earlier classes. It may also be that, as the women in the classes of 1995-99 progress through their life-cycle, enough will leave private practice and undertake other opportunities so that their type of practice distribution will look more like that of the women of the classes of 1985-89. Probably both generational and life-cycle factors are at play. Studying the phenomenon over time is the only way to effectively separate the two effects, and we attempt to do this with the data in table 13 below.

The data in tables 11 and 12 indicate that our Black and Hispanic alumni do not place as well across the profession as majority men and women. Blacks are underrepresented throughout private practice for both the classes of 1985-89 and 1995-99, while Hispanics are underrepresented in all types of private practice except super private firms for the classes of 1985-89 and 1995-99, and small private practices for the classes of 1995-99. Both Blacks and Hispanics are overrepresented in corporate counsel, government work, and public interest work, except for corporate counsel work in the classes of 1985-89. Some of this variation in the type of practice engaged in by our majority and minority alumni is undoubtedly due to differences in opportunities. However, some of the variation may also be due to differences in preferences. As seen in tables 9 and 10, our minority alumni place a higher emphasis on achieving social impact in their career, and they may choose government and corporate counsel work in greater proportion because it affords them that opportunity. There is only weak support for a "different preferences" hypothesis in the reported career plans of our minority alumni in tables 7 and 8 , and a lot of evidence that our minority alumni have plans to go into super or large private firms that are never realized. Once again, the small numbers of our Black and Hispanic alumni make it difficult to draw meaningful conclusions, although that fact in itself speaks volumes. Although Blacks and Hispanics have made significant strides in the legal profession in recent years, that progress pales in comparison with the advances achieved by women. 22

Table 13 presents data on the first job out of law school reported by the classes of 1985-89. Although these data are not strictly comparable with the data in table 12 because there was significant growth in law firms in the time between 1985-89, when

21. One female alumnus reported that large corporate clients sometimes require significant work on their cases by minority and female attorneys as a condition of doing business. The two specific examples of such corporations she gave were Sears and Wal-mart.

22. For a more extensive study of the minority alumni of the University of Michigan Law School, see Richard O. Lempert, David L. Chambers \& Terry K. Adams, Michigan's Minority Graduates in Practice: The River Runs Through Law School, 25 LAW \& Soc. INQUIRY 395 (2000). 
these first jobs were obtained, and 2000-04, when the status in table 12 was observed, they do suggest some life-cycle movement among different types of practice by both men and women in the first fifteen years of practice. The data suggest that over the first fifteen years of practice, both the men and women of the classes of 1985-89 have moved from private practice to corporate counsel positions, government work and "other" positions. This movement is somewhat more pronounced among the female alumni than among the male alumni. Over their first fifteen years, the men in the classes of $1985-89$ have moved from $71.5 \%$ in private practice to $46.8 \%$ in private practice while the women have moved from $56.3 \%$ in private practice to $25.7 \%$ in private practice. The losses are greatest among the largest private firms, and the gains are greatest in the "other" category. ${ }^{23}$ In examining this phenomenon, it becomes all the more apparent that it is important to understand what our alumni are doing in the "other" category.

Table 13. Percent of respondents to the fifteen-year survey of Indiana classes 1985-89 in each type of first job

\begin{tabular}{lccc}
\hline Variable & All observations & Men & Women \\
\hline $\begin{array}{l}\text { Super-size priv. prac. } \\
\text { (\# attys. >150) }\end{array}$ & 14.9 & 16.7 & 11 \\
$\begin{array}{l}\text { Large priv. prac. } \\
(150>=\text { \# attys. }>50)\end{array}$ & 14.1 & 15.5 & 11 \\
$\begin{array}{l}\text { Medium priv. prac. } \\
\text { (50 >= \# attys. > 15) }\end{array}$ & 14.5 & 16.1 & 11 \\
$\begin{array}{l}\text { Small priv. prac. } \\
(15>=\text { \# attys.) }\end{array}$ & 23.2 & 23.2 & 23.3 \\
Corporate counsel & 4.1 & 4.8 & 2.7 \\
Government & 13.7 & 13.1 & 15.1 \\
Public interest & 4.6 & $3.0^{*}$ & $8.2 * *$ \\
Other & 10.8 & $7.7^{* *}$ & $17.8^{* *}$ \\
Number & 241 & 168 & 73 \\
\hline
\end{tabular}

NOTE: ${ }^{*}=$ significant at 0.1 level; ${ }^{* *}=$ significant at 0.05 level, one-tailed test.

Tables 14 and 15 present the available information on the careers of the "other" respondents in the classes of 1985-89 who are not practicing law, or at least not practicing in one of the traditional settings already discussed in this Article. In the survey we asked each respondent to identify the firm or agency they worked for and

23. Examining the life-cycle phenomenon on the movement of our alumni among different types of practice from the perspective of the classes of 1995-99, the results of our survey suggest that, even five years after graduation, female alumni express a greater propensity to move from one job to another. In the survey we asked our alumni whether, in five years, they would be practicing in the same firm or agency as they are now and recorded four answers: "yes" (+2), "probably yes" (+1), "probably not" (-1), and "no" (-2). For the classes of 1995-99, the mean for men for this variable was 1 and the mean for women was 0.5 , and the difference was significant at the $\mathbf{0 . 0 5}$ level. The possible reasons alumni gave for leaving their present place of work were textually recorded. Searching the text record for women, we find thirteen references to family or children. Searching the text record for men, we find two references to family. 
their position with that entity. Table 14 displays the reported firm or agency for which the "other" respondents worked, displayed in percentage terms and broken down according to gender. Table 15 displays the reported position the "other" respondents held with that firm or agency, displayed in percentage terms and broken down according to gender. The results show that our alumni in the classes of 1985-89 who are in "non-traditional" careers work for governments, educational institutions, and businesses, and occupy positions such as judges, elected or appointed officials, law professors, other teachers, and business managers. The largest career category among those in "non-traditional" careers is business executive, director, or manager, accounting for almost $42 \%$ of those in the "other" category. Other strong categories include judge $(12.5 \%)$, teacher $(10.9 \%)$, and elected or appointed official $(7.3 \%)$. The men seem to disproportionately work for business, while the women seem to disproportionately work for the government and educational institutions. Following this general division between the genders, men are disproportionately found among the business managers ( $44.4 \%$ to $36.8 \%$ ) while the women are disproportionately found among the judges ( $15.8 \%$ to $11.1 \%$ ), public officials $(10.6 \%$ to $5.6 \%$ ), and the law professors (5.3\% to $0 \%$ ). Although it is gratifying to see the great diversity and success our alumni enjoy in their careers outside the traditional practice of law, it would be a mistake to make too much of the variation between the genders within each category because these results are based on such a small sample. Despite our best efforts to identify all careers, there are still a number of "others" reported among those in "nontraditional" careers.

Table 14. What are "others" doing? Percent of respondents in "other" category in the classes of 1985-89 surveyed fifteen years out of law school and what they are doing

\begin{tabular}{lccc}
\hline Type of work & All observations & Men & Women \\
\hline Government & 25 & 20.9 & 33.3 \\
Educational institution & 12.5 & 9.3 & 19 \\
Fortune 500 business & 9.4 & 14 & 0 \\
Bank & 4.7 & 7 & 0 \\
Accounting firm & 1.6 & 2.3 & 0 \\
Insurance & 3.2 & 2.3 & 4.8 \\
Other business & 20.3 & 25.6 & 9.5 \\
Other & 23.4 & 18.6 & 33.3 \\
Number of observations & 64 & 43 & 21 \\
\hline
\end{tabular}

Table 15. What are "others" doing? Percent of respondents in "other" category in the classes of 1985-89 surveyed fifteen years out of law school and their position

\begin{tabular}{lccc}
\hline Variable & All observations & Men & Women \\
\hline Judge & 12.7 & 11.1 & 15.8 \\
Elected or appointed official & 7.3 & 5.6 & 10.6 \\
Executive, director, manager & 41.8 & 44.4 & 36.8 \\
Staff member & 3.6 & 5.6 & 0 \\
Law professor & 1.8 & 0 & 5.3
\end{tabular}




\begin{tabular}{lccc}
\hline Variable & All observations & Men & Women \\
\hline Other teacher & 9.1 & 11.1 & 5.3 \\
Other & 23.6 & 22.2 & 26.3 \\
Number of observations & 55 & 36 & 19 \\
\hline
\end{tabular}

\section{Income, Hours, Job Satisfaction, and Satisfaction with Work/Family Balance}

Continuing our examination of alumni careers, we next consider the income and satisfaction our alumni enjoy in their chosen areas of practice. Students and alumni are naturally curious about the income and satisfaction experienced by others in various types of practice, and such information can be useful in making career choices. It is also useful to examine the income and satisfaction enjoyed by our alumni, separated according to gender, race, and ethnicity, in order to evaluate the success of the profession and the law school in meeting the needs of all of its members. In this Part, we examine how variables such as income, hours worked, and job and family satisfaction levels vary by type of practice, gender, and minority status. Finally, we examine how our alumni in private practice have progressed through the course of their careers by examining the percentage that make partner.

\section{Type of Practice}

Tables 16 and 17 present data on income, satisfaction, and hours of work for the classes of 1995-99 and 1985-89, respectively, broken down by type of practice. The annual income row records the mean annual income reported in thousands of 2004 dollars. Annual hours worked reports the mean total hours worked (as opposed to billable hours) based on the respondents' answers. The usual hourly fee is expressed in 2004 dollars/hour and is, once again, the mean value based on respondents' answers. The three satisfaction variables are evaluated on a seven point scale, ranging from "very unsatisfied" $(-3)$ to "very satisfied" $(+3)$, as described in Part II. Respondents indicated their degree of satisfaction with their job, their family life, and the balance between their work and family. A higher number represents greater satisfaction and, following our rule-of-thumb for satisfaction variables, a one-point jump in these variables near the mean equates to passing approximately $34 \%$ of the distribution for all respondents. Annual hours pro bono and the percentage of time working for middle class or low-income clients are variables that help evaluate the type of client our alumni serve. Again, the reported numbers are mean values based on our alumni's survey responses. As in tables 11 and 12, a "super" private firm is one which employs more than 150 lawyers, a "large" private firm employs between 50 and 150 lawyers, a "medium" private firm employs between 15 and 50 lawyers, and a "small" private firm employs less than 15 lawyers. 
Table 16. Selected means for respondents to the five-year survey from Indiana classes of 1995-99

\begin{tabular}{|c|c|c|c|c|c|c|c|c|}
\hline Variable & All obs. & $\begin{array}{c}\text { Super } \\
\text { private }\end{array}$ & $\begin{array}{c}\text { Large } \\
\text { private }\end{array}$ & $\begin{array}{c}\text { Medium } \\
\text { private }\end{array}$ & $\begin{array}{c}\text { Small } \\
\text { private }\end{array}$ & $\begin{array}{c}\text { Corporate } \\
\text { counsel }\end{array}$ & Gov't & $\begin{array}{l}\text { Public } \\
\text { interest }\end{array}$ \\
\hline $\begin{array}{l}\text { Annual income } \\
\text { (in thousands of } \\
2004 \text { dollars) }\end{array}$ & 86.3 & $118.9 * *$ & 90.2 & 80.6 & 84.3 & $96.3^{*}$ & $57.8 * *$ & $57.9^{* *}$ \\
\hline $\begin{array}{l}\text { Annual hours } \\
\text { worked }\end{array}$ & 2440 & $2632 * *$ & 2468 & 2481 & 2482 & 2364 & 2410 & $2094^{* *}$ \\
\hline Usual hourly fee & 178 & $217 * *$ & 183 & 173 & $156^{* *}$ & 141 & $102^{* *}$ & $105^{*}$ \\
\hline Job satisfaction & 1.32 & $1.57^{* *}$ & 1.42 & $0.97 * *$ & $1.13^{*}$ & $1.64 * *$ & 1.31 & 1.54 \\
\hline $\begin{array}{l}\text { Family } \\
\text { satisfaction } \\
\text { Satisfaction with } \\
\text { family/work } \\
\text { balance }\end{array}$ & 1.85 & $0.19^{* *}$ & $0.16^{* *}$ & $0.17 * *$ & 1.92 & $2.29 * *$ & 1.69 & 1.57 \\
\hline $\begin{array}{l}\text { Annual hours pro } \\
\text { bono } \\
\% \text { Time work for } \\
\text { middle income or } \\
\text { poor }\end{array}$ & 22.2 & $1.6 * *$ & $1.4^{* *}$ & $10.0^{* *}$ & $54.3^{* *}$ & $10.2^{* *}$ & $10.6^{* *}$ & $72.3^{* *}$ \\
\hline Number & 325 & 47 & 25 & 36 & 64 & 27 & 50 & 14 \\
\hline
\end{tabular}

NOTE: * = significant at 0.1 level; $* *=$ significant at 0.05 level, one-tailed test.

Table 17. Selected means for respondents to the fifteen-year survey of the Indiana classes of 1985-89

\begin{tabular}{|c|c|c|c|c|c|c|c|c|}
\hline Variable & All obs. & $\begin{array}{c}\text { Super } \\
\text { private }\end{array}$ & $\begin{array}{c}\text { Large } \\
\text { private }\end{array}$ & $\begin{array}{c}\text { Medium } \\
\text { private }\end{array}$ & $\begin{array}{c}\text { Small } \\
\text { private }\end{array}$ & $\begin{array}{c}\text { Corporate } \\
\text { counsel }\end{array}$ & Gov't & $\begin{array}{c}\text { Public } \\
\text { interest }\end{array}$ \\
\hline $\begin{array}{l}\text { Annual income } \\
\text { (in thousands of } \\
2004 \text { dollars) }\end{array}$ & 151.0 & $241.8 * *$ & $244 * *$ & 196.5 & $131.8^{*}$ & 153.7 & $74.9^{* *}$ & $62.7^{* *}$ \\
\hline $\begin{array}{l}\text { Annual hours } \\
\text { worked }\end{array}$ & 2262 & 2377 & 2457 & 2204 & 2237 & $2409 * *$ & 2223 & $2068^{*}$ \\
\hline Usual hourly fee & 208 & $304 * *$ & $271^{* *}$ & 204 & $166^{* *}$ & 179 & $83 * *$ & N/A \\
\hline Job satisfaction & 1.66 & $1.38^{*}$ & 1.64 & 1.30 & 1.52 & 1.61 & 1.83 & 1.50 \\
\hline $\begin{array}{l}\text { Family } \\
\text { satisfaction } \\
\text { Satisfaction with } \\
\text { family/work } \\
\text { balance }\end{array}$ & 1.82 & 1.50 & $2.21 * *$ & 2.00 & 1.56 & 2.04 & 1.53 & 1.63 \\
\hline $\begin{array}{l}\text { Annual hours pro } \\
\text { bono } \\
\% \text { Tme work for } \\
\text { middle income or } \\
\text { poor }\end{array}$ & 27.9 & $14.9 * *$ & $4.8^{* *}$ & $7.0^{* *}$ & $49.7^{* *}$ & $6.7^{* *}$ & $8.1 * *$ & $100.0^{* *}$ \\
\hline Number & 224 & 16 & 14 & 10 & 52 & 23 & 30 & 8 \\
\hline
\end{tabular}

NOTE: * = significant at 0.1 level; ** = gnificant at 0.05 level, one-tailed test.

With respect to income, our results are predictable in that those alumni who work in super and large private practices report the highest average incomes, while those in government and public interest work report the lowest. Although this result was expected, the magnitude of the mean difference in attorneys' salaries according to type of practice was not. Attorneys in super and large private firms make approximately 
twice the amount earned by government and public interest lawyers five years out of law school, reporting averages of $\$ 118,900$ and $\$ 90,000$ respectively, while attorneys in government work and public interest report making an average of approximately $\$ 57,800$. By fifteen years out of law school, the advantage of large private practice attorneys has grown to over three-fold with attorneys in super and large firms reporting average incomes in excess of $\$ 241,000$ and government and public interest attorneys reporting average incomes of only $\$ 74,900$ and $\$ 62,700$ respectively! Corporate counsel attorneys also do very well on income, reporting an average of $\$ 96,300$ five years out, and $\$ 153,700$ fifteen years out of law school. Attorneys in medium and small-sized firms also do well with income, although not as well as their classmates in the larger firms. Figure 1 displays the relative average income differences between the different types of practice reported by the classes of 1995-99 five years out of law school and the classes of 1985-89 fifteen years out of law school.

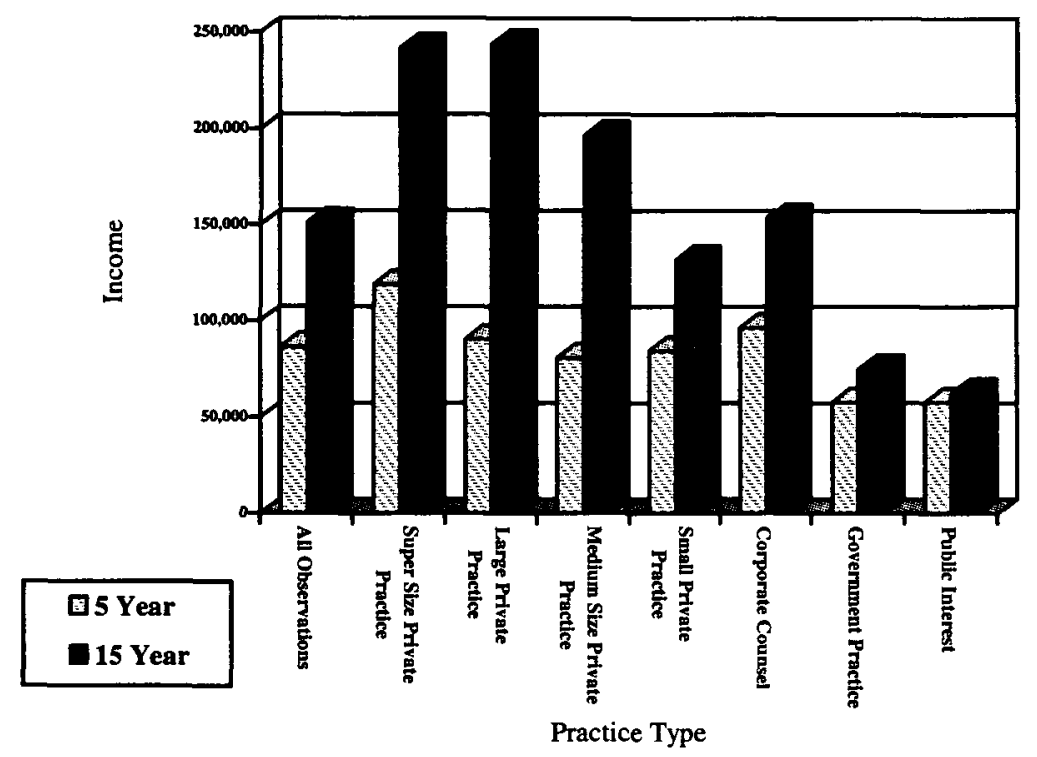

Figure 1. Income by type of practice (five and fifteen years after law school) in 2004 dollars.

Our alumni across all types of practice report much satisfaction with their work and families. This finding is at odds with some studies of other groups of lawyers which report much dissatisfaction with the profession. ${ }^{24}$ Our alumni in super private firms and

24. See Keith Cunningham, Father Time: Flexible Work Arrangements and the Law Firm's Failure of the Family, 53 STAN. L. REV. 967, 969-70 (2001); Patrick J. Schiltz, On Being $a$ Happy, Healthy, and Ethical Member of an Unhappy, Unhealthy, and Unethical Profession, 52 VAND. L. REV. 871, 881-82 (1999). But see Kathleen E. Hull, Cross-Examining the Myth of Lawyers' Misery, 52 VAND. L. REV. 971 (1999); John P. Heinz, Kathleen E. Hull, \& Ava A. Harter, Lawyers and Their Discontents: Findings from a Survey of the Chicago Bar, 74 IND. L. J. 735 (1999). For a neutral analysis of the satisfaction literature, see Stephen D. Easton, $M y$ Last Lecture: Unsolicited Advice for Future and Current Lawyers, 56 S.C. L. REV. 229 (2004) 
working as corporate counsel report being significantly more satisfied with their job five years out, while those in medium and small private firms report being significantly less satisfied, although their mean is still significantly greater than zero. Fifteen years out of law school, these differences have largely abated, although attorneys in super private firms now report being significantly less satisfied than their classmates in other types of practice. All subgroups of our alumni report high satisfaction with their families, although attorneys in super, large, and medium-sized private firms report very low satisfaction with their ability to balance work and family responsibilities. Undoubtedly, the low levels of satisfaction with family/work balance reported by those in the larger private practices are at least in part attributable to the long hours those practices require. Although female alumni have related a preference for large firms to become more flexible with family/work balance, small private firms appear to do very well in this regard. This result is perhaps due to attorneys organizing their individual or small practices in such ways as to facilitate child care and family time.

Corporate counsel positions seem a good mix of income, job satisfaction, and satisfaction with family/work balance, although they seem to become more burdensome, rather than less as our alumni progress from five years out of law school to fifteen years out. Lawyers in corporate counsel receive exciting assignments, long but reasonable hours, opportunities for flexibility in schedules, prestige, and management opportunities not normally found in the traditional private practice. ${ }^{25} \mathrm{Our}$ alumni employed as corporate counsel appear to be faring quite well in this setting. At the other end of the spectrum, and perhaps surprisingly, the results from respondents five years out of law school suggest that those in medium firms are, relative to other graduates, least satisfied. Those in medium firms report relatively low income while working comparable hours. These graduates report the lowest job satisfaction, a relatively low family satisfaction, and the lowest satisfaction with family/work balance. However, the satisfaction variables for alumni in medium-sized private practices rebound nicely fifteen years out of law school, showing comparable satisfaction with job and family, and the highest satisfaction with family/work balance, although this result is not statistically significant. These results weakly suggest that practice in a medium-sized private firm is more family friendly, at least later in one's career, than is commonly perceived. Figure 2 displays the levels of job satisfaction by type of practice for both our samples. Figure 3 presents the levels of satisfaction with family/work balance reported by our alumni five years out and fifteen years out of law school, broken down by type of practice.

(concluding that different environments will present different challenges for lawyers and advising all to be honest with themselves regarding their abilities and aspirations, and to choose positions wisely).

25. Joan C. Williams, Cynthia Thomas Calvert \& Holly Cohen Cooper, Better on Balance? The Corporate Counsel Work/Life Report, 10 WM. \& MARY J. WOMEN \& L. 367 (2004) (finding through qualitative analysis that those in corporate counsel positions generally worked long hours (around 50 hours/week), but not as long as traditionally worked by private-firm associates). Scheduling flexibility, when present, is not due necessarily to part-time positions, but rather to supportive and cooperative departments which share responsibilities. Ultimately, each firm is different in its utilization of in-house legal departments. Generalizations such as those offered in this article are simply dependent on the sample of corporate lawyers. 


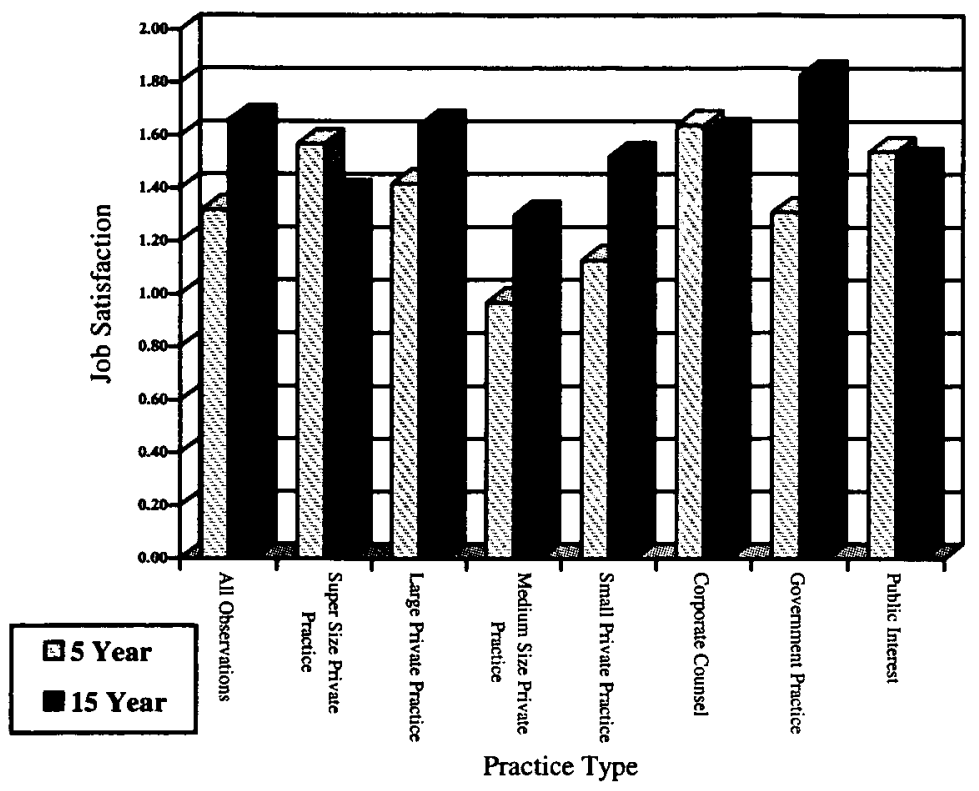

Figure 2. Job satisfaction by type of practice (five and fifteen years after law school).

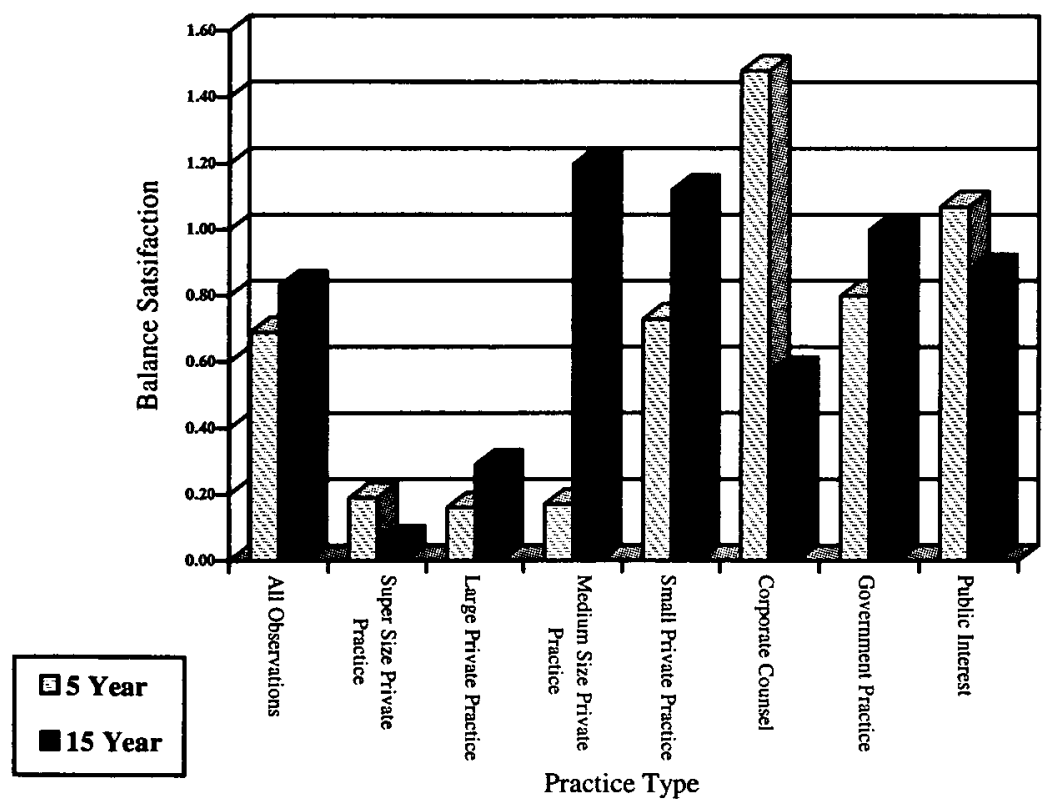

Figure 3. Satisfaction with family/work balance by type of practice (five and fifteen years after law school).

In a previous study, two of the authors found an inverse relationship between income and job satisfaction across the legal profession using data from University of 
Michigan Law alumni. ${ }^{26}$ That is to say that the authors found that attorneys in the highest paid types of practice (super and large private firms) reported the lowest job satisfaction while those in the lowest paid types of practice (government and public interest work) reported the highest job satisfaction. Noting that both income and job satisfaction were desirable attributes of a job, the authors hypothesized that those attorneys in the types of practice with higher average income were trading job satisfaction for higher income, while those in the types of practice with lower average income were trading income for higher job satisfaction. Such an inverse relationship between income and job satisfaction is more difficult to detect in the data from our Indiana Law alumni. Indeed, for the classes of 1995-99, those attorneys in super private practice and corporate counsel positions, both of which boast high incomes, report a significantly higher level of job satisfaction. Of course, there are other attributes one might look for in a job including quality of life, firm flexibility, and time off to spend with your family. ${ }^{27}$ It may be that a larger proportion of Indiana Law alumni in super or large private firms work in the Midwest than their Michigan counterparts, contributing to their quality of work life and job satisfaction. The data from the classes of 1985-89 falls closer in line with the inverse income-job satisfaction relationship observed in the Michigan data, although there are still variations from this theme. Those in super firms report significantly lower job satisfaction levels, although the positive value indicates that even these graduates are satisfied with their work.

\section{Gender and Minority Status}

Tables 18 and 19 examine the same income and satisfaction variables presented in tables 16 and 17 and described above, broken down by gender and minority status. Again, the annual income is listed in thousands of 2004 dollars. Annual hours worked is the total number of hours the respondents reported working (as opposed to billable hours). The usual hourly fee is expressed in dollars/hour. And again, the three satisfaction variables were based on a seven point scale, ranging from "very unsatisfied" $(-3)$ to "very satisfied" $(+3)$, where respondents indicated their degree of satisfaction with their job, their family life, and their family/work balance. The more positive the number, the greater the level of expressed satisfaction.

26. Kenneth G. Dau-Schmidt \& Kaushik Mukhopadhaya, The Fruits of Our Labors: An Empirical Study of the Distribution of Income and Job Satisfaction Across the Legal Profession, 49 J. LEG. EDUC. 342, 365 (1999).

27. Indeed, in a study of Texas attorneys, Susan Fortney has found lower billable hours as largely determinative of job satisfaction. Susan Saab Fortney, Soul for Sale: An Empirical Study of Associate Satisfaction, Law Firm Culture, and the Effects of Billable Hour Requirements, 69 UMKC L. REV. 239, 267 (2000). 
Table 18. Selected means for respondents to the five-year survey of Indiana classes of 1995-99

\begin{tabular}{|c|c|c|c|c|c|c|c|}
\hline Variable & $\begin{array}{c}\text { All } \\
\text { observations }\end{array}$ & Men & Women & Non-Black & Black & $\begin{array}{c}\text { Non- } \\
\text { Hispanic }\end{array}$ & Hispanic \\
\hline $\begin{array}{l}\text { Annual income } \\
\text { (thousands of } \\
2004 \text { dollars) }\end{array}$ & 86.0 & $92.5 * *$ & $77.0^{* * *}$ & $87.1^{* *}$ & $72.7 * *$ & 85.3 & 106.8 \\
\hline $\begin{array}{l}\text { Annual hours } \\
\text { worked }\end{array}$ & 2439 & $2529 * *$ & $2314 * *$ & 2438 & 2427 & 2445 & 2230 \\
\hline Usual hourly fee & 177 & $185^{* *}$ & $163^{* *}$ & 177.8 & 175.8 & 174.4 & 256.5 \\
\hline Job satisfaction & 1.32 & 1.36 & 1.27 & 1.33 & 1.23 & 1.32 & 1.36 \\
\hline $\begin{array}{l}\text { Family } \\
\text { satisfaction }\end{array}$ & 1.85 & $1.70^{* *}$ & $2.01 * *$ & $1.86^{*}$ & $1.45^{*}$ & 1.82 & 2.25 \\
\hline $\begin{array}{l}\text { Satisfaction with } \\
\text { family/work } \\
\text { balance }\end{array}$ & 0.69 & 0.69 & 0.69 & 0.69 & 0.55 & 0.67 & 1.08 \\
\hline $\begin{array}{l}\text { Annual hours pro } \\
\text { bono } \\
\text { \% Time work for } \\
\text { middle income or } \\
\text { poor }\end{array}$ & 21.9 & 22.6 & 20.4 & $20.8^{*}$ & $36.4^{*}$ & 21.0 & 35.5 \\
\hline Number & 337 & 196 & 141 & 314 & 22 & 324 & 12 \\
\hline
\end{tabular}

NOTE: * = significant at 0.1 level; ** = significant at 0.05 level, one-tailed test.

Table 19. Selected means for respondents to the fifteen-year survey of the Indiana classes of 1985-89

\begin{tabular}{|c|c|c|c|c|c|}
\hline Variable & All observations & Men & Women & $\begin{array}{c}\text { Non-Black } \\
\text { Non-Hispanic }\end{array}$ & $\begin{array}{l}\text { Black or } \\
\text { Hispanic }\end{array}$ \\
\hline $\begin{array}{l}\text { Annual income } \\
\text { (thousands of } \\
2004 \text { dollars) }\end{array}$ & 149.9 & $173.1 * *$ & $92.5 * *$ & 151.5 & 118.3 \\
\hline $\begin{array}{l}\text { Annual hours } \\
\text { worked }\end{array}$ & 2207 & $2347^{* *}$ & $1877 * *$ & 2216 & 2128 \\
\hline Usual hourly fee & 206 & $211^{*}$ & $183^{*}$ & 205 & 234 \\
\hline $\begin{array}{l}\text { Job satisfaction } \\
\text { Family }\end{array}$ & 1.63 & 1.59 & 1.74 & $1.61^{* *}$ & $2.00^{* *}$ \\
\hline $\begin{array}{l}\text { satisfaction } \\
\text { Satisfaction with } \\
\text { family/work }\end{array}$ & 1.85 & $1.70^{* *}$ & $2.16^{* *}$ & 1.85 & 1.60 \\
\hline balance & 0.87 & 0.80 & 1.03 & 0.87 & 0.30 \\
\hline $\begin{array}{l}\text { Annual hours pro } \\
\text { bono }\end{array}$ & 55 & 57 & 50 & $57^{* *}$ & $7^{* *}$ \\
\hline $\begin{array}{l}\% \text { Time work for } \\
\text { middle income or } \\
\text { poor }\end{array}$ & 29.1 & 27.2 & 34.9 & 28.6 & 48.3 \\
\hline Number & 240 & 166 & 74 & 229 & 10 \\
\hline
\end{tabular}

NOTE: * = significant at 0.1 level; ${ }^{* *}=$ significant at 0.05 level, one-tailed test.

Examining tables 18 and 19 , we see a number of differences associated with gender. Women report a significantly lower average income than men, earning $\$ 77,000$ on 
average five years out of law school, while men earn $\$ 92,500$. By fifteen years out of law school, this difference in average income has grown and women report earning $\$ 92,500$, while the men report earning $\$ 173,100 .^{28}$ In part this difference in average income is explained by the fact that women report working significantly fewer hours than men, both five ( 2314 hours for women to 2529 hours for men) and fifteen years after law school (1877 hours for women to 2347 hours for men). As we have seen before, our male alumni also express a greater interest in money and are more likely to be the primary breadwinner, while our female alumni do much more childcare and tend to be found in the lower-paying types of practice that facilitate family responsibilities (especially in the fifteen-year sample) ${ }^{29}$ Both women and men report similar levels of job satisfaction and satisfaction with the family/work balance. Women are significantly more satisfied than men with their family lives both five and fifteen years out of law school. ${ }^{30}$ One interesting non-difference is that women and men report approximately the same percentage of time working for middle income people and the poor and the same amount of time doing pro bono work. These results are somewhat surprising because women report being more compassionate and interested in social impact than men, and are found in greater proportions in government and public interest work. However, men are disproportionately found in small and medium private law firms, which spend approximately half of their time representing the middle class and the poor. $^{31}$

Examining tables 18 and 19 for differences associated with minority status, we find that, once again, our analysis is limited by a paucity of minority observations. The responses of our Black and Hispanic alumni from the classes of 1985-89 are combined in table 19. Our Black alumni report significantly lower income than non-Blacks five years out of law school $(\$ 72,700$ versus $\$ 87,100)$, and Black and Hispanic alumni report lower income fifteen years out of law school $(\$ 118,300$ versus $\$ 151,500)$, but this difference is not statistically significant. Interestingly, our Hispanic alumni report a higher average income five years out of law school, but this result is not significant. Blacks report significantly lower family satisfaction five years out (1.45 to 1.86) than non-Blacks, which may be due to the fact that Blacks are much more likely to have a spouse with an intense job. ${ }^{32}$ Our Black alumni do nearly twice as many hours of pro bono work as non-Blacks five years out ( 71 hours to 37 hours) and spend significantly more of their time working for middle class or poor clients (36.4 to 20.8). The lower

28. See also Cathlin Donell, Joyce Sterling \& Nancy Reichman, Gender Penalties: The RESUlTS OF THE CAREERS AND COMPENSATION STUdY (Colorado Women's Bar Association 1998) (examining the differences in pay between men and women in the legal profession); Robert G. Wood, Mary E. Corcoran \& Paul N. Courant, Pay Differences Among the Highly Paid: The Male-Female Eamings Gap in Lawyers' Salaries, 11 J. LAB. ECoN. 417 (1993) (same).

29. See supra tables $9 \& 10$.

30. This finding is consistent with other empirical results that find women lawyers reporting higher job and family satisfaction than men. See Kathleen E. Hull, The Paradox of the Contented Female Lawyer, 33 LAw \& Soc'y REv. 687, 689-96 (1999). See also David L. Chambers, Accommodation and Satisfaction: Women and Men Lawyers and the Balance of Work and Family, 14 LAW \& SOC. INQUIRY 251 (1989).

31. See supra tables $11 \& 12$.

32. See supra table 9. 
income and higher percentage of time working for middle class or poor clients is not surprising given the distribution of our Black graduates across the legal profession. As seen in table 11, our Black alumni five years away from law school are disproportionately represented in the public interest and government sectors, and underrepresented in the super and large private firms. Our Black alumni also report that they view themselves as more compassionate than other lawyers and that they have a greater desire for social impact. Figure 4 displays satisfaction with the family by gender and minority status for both alumni five and fifteen years after law school. Figure 5 displays satisfaction with the family/work balance by gender and minority status for both sets of alumni.

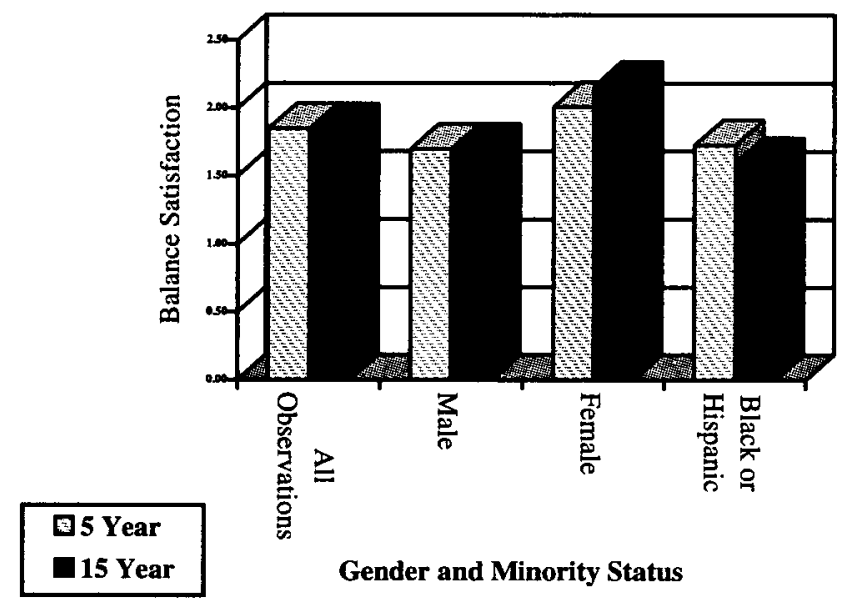

Figure 4. Satisfaction with the family by gender and minority status (five and fifteen years after law school).

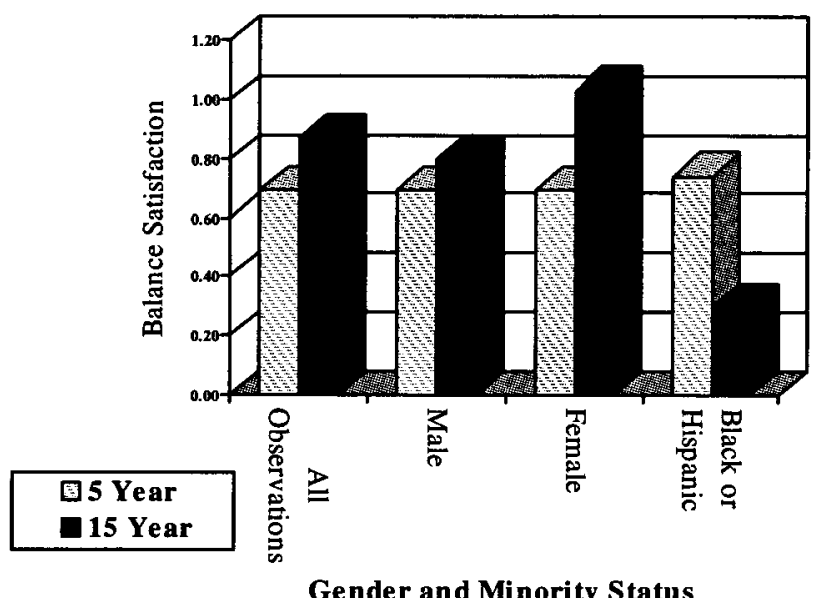

Figure 5. Satisfaction with family/work balance by gender and minority status (five and fifteen years after law school). 


\section{How Are Our Alumni Progressing in Their Careers in Private Practice?}

The traditional mark of achievement in private practice is an attorney's acceptance as a partner in a firm. "Partnership" is the goal that many of our alumni in private practice strive to achieve, and whether they succeed in attaining this final step up the ladder toward professional success can have a huge impact on their remuneration and happiness in the practice of law. For others, however, who dislike the hours of work and sacrifice of time with family required to make and maintain partnership, partnership is not the proverbial "light at the end of the tunnel," but instead a "cave." In this Part, we examine data on our alumni of the classes of 1985-89 in private practice, collected fifteen years after law school, to determine how our alumni have advanced in their private practice careers and whether there are systematic variations associated with gender, race, or ethnicity.

Table 20 presents the percentage of the classes of 1985-89 in private practice according to the current status the alumni report in their firm. The results are broken down according to gender, race, and ethnicity. Unfortunately, once again, there are not enough observations to make any useful generalizations about partner selection based on minority status. As table 20 indicates, the majority of men and women in private practice fifteen years after law school are partners in their respective firms. A significantly higher percentage of men than women currently report themselves as being a partner $(71.8 \%$ versus $52.6 \%) .{ }^{34}$ Fifteen years after law school, women are disproportionately found in "of counsel" positions, while significantly more men still have the title of "associate." No women in our sample were associates fifteen years out, while almost $5 \%$ of men were associates at that point in time. A surprisingly high number of women report themselves as practicing "solo," given our prior results suggesting that women avoid small and medium firm practice, although the result is not statistically different from the men.

Table 20. Percent of respondents in the fifteen-year survey of Indiana classes 1985-89 who are partner, associate, and of counsel

\begin{tabular}{lccccc}
\hline Variable & All observations & Men & Women & $\begin{array}{c}\text { Non-Black Non- } \\
\text { Hispanic }\end{array}$ & $\begin{array}{c}\text { Black or } \\
\text { Hispanic }\end{array}$ \\
\hline Partner & 68.3 & $71.8^{*}$ & $52.6^{*}$ & 67.7 & 75 \\
Associate & 3.8 & $4.7^{* *}$ & $0.0^{* *}$ & $4.0^{* *}$ & $0.0^{* *}$ \\
Of counsel & 7.7 & $4.7^{*}$ & $21.0^{*}$ & 7.1 & 25 \\
Solo & 20.2 & 18.8 & 26.3 & $21.2^{* *}$ & $0.0^{* *}$ \\
Number & 104 & 85 & 19 & 100 & 4 \\
\hline
\end{tabular}

NOTE: * = significant at 0.1 level; $* *=$ significant at 0.05 level.

33. See Nat'l Ass'N for Law Placement Foundation for Research and EduC.,

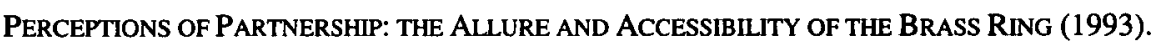

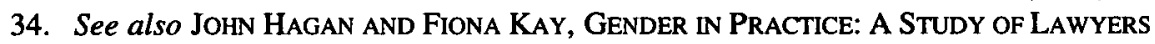
Lives (1995); Cynthia Fuchs Epstein, Robert Sauté, Bonnie Oglensky \& Martha Gever, Report: Glass Ceilings and Open Doors: Women's Advancement in the Legal Profession, 64 FORDHAM L. REV. 291 (1995). 
The most likely explanation for this difference between the partnership and associate status of men and women seems to be childcare responsibilities. As noted above, our alumni often follow traditional gender roles regarding childcare and income production with the women undertaking greater responsibilities for childcare, while the men are more often the primary breadwinner. This is especially true of our alumni fifteen years after law school. Though women enter private practice at a rate only somewhat lower than their male peers, women seem primarily drawn to large firm practice, perhaps by the money and prestige, or perhaps by the promises of familyflexible arrangements. Once in private practice, as the women have children, many of them become "of counsel" or work "solo" on a contract basis, so as to gain more flexibility for family responsibilities. Some women may even achieve partnership and then leave this status to become "of counsel" and take on childcare. ${ }^{35}$ Men do not have this option as a socially acceptable alternative, and those who do not make "partner" and do not have alternatives with another office, hang on for the hours of work and income as an "associate" despite the indignity of the situation. A quick check of the difference in childcare responsibilities between women who are "partners" and those who are "of counsel" is consistent with this analysis. 20\% of women "partners" report ever not working or working part time to take on childcare, while $75 \%$ of the women who are "of counsel" report doing the same.

Of course, as we saw in table 13 , over the first fifteen years of practice, there is some movement by our alumni out of private practice to corporate counsel, government, and other careers. This movement out of private practice is more pronounced among women than among men. Table 21 presents the percentage of our alumni of the classes of 1985-89 surveyed fifteen years after law school who started in private practice in their first job after law school ${ }^{36}$ and who are a partner in some private practice firm fifteen years later. Overall, $39.6 \%$ of those alumni who started in private practice are a partner fifteen years later. A significantly higher percent of men who start in private practice are partners fifteen years later $(48.3 \%$ ) than of similarly situated women $(15.9 \%)$. This difference between the genders appears in all sizes of firms and is perhaps strongest in medium-sized firms. Although those alumni who start in medium-sized firms and are partners fifteen years later form the largest percentage (55.3\%), there does not seem to be a consistent relationship between size of initial firm and making partner. Those alumni who start in supersized firms are the next most likely to be a partner fifteen years later $(41.7 \%)$, and those who start in small firms are the least likely $(30.4 \%)$, although it may be that some respondents in small or solo practices resisted calling themselves partners.

35. Our discussions with both male and female Indiana alumni in focus groups suggest that this occurs surprisingly often.

36. The survey question expressly excluded judicial clerkships when asking about the alum's "first job" after law school. 
Table 21. Percent of respondents in the fifteen-year survey of Indiana classes 1985-89 who start in private practice in their first job after law school and are a partner fifteen years after law school

\begin{tabular}{lcccc}
\hline $\begin{array}{l}\text { Percent who are a partner fifteen } \\
\text { years after law school }\end{array}$ & All & Male & Female & $\begin{array}{c}\text { Number of } \\
\text { observations }\end{array}$ \\
\hline $\begin{array}{l}\text { Start in private practice (all firms) } \\
\text { Start in a supersized private firm } \\
\text { (\# attys. }>150)\end{array}$ & 39.6 & $48.3^{* *}$ & $15.9^{* *}$ & 164 \\
$\begin{array}{l}\text { Start in a large private firm } \\
(150>=\text { \# attys. }>50)\end{array}$ & 41.7 & $46.4^{*}$ & $25.0^{*}$ & 36 \\
$\begin{array}{l}\text { Start in a medium-sized private firm } \\
(50>=\text { \# attys. }>15)\end{array}$ & 33.3 & $40.0^{* *}$ & $12.5^{* *}$ & 34 \\
$\begin{array}{l}\text { Start in a small private firm } \\
(15>=\text { \# attys.) }\end{array}$ & 55.3 & $70.4^{* *}$ & $18.2^{* *}$ & 38 \\
\begin{tabular}{l} 
Number of observations \\
\hline
\end{tabular} & 30.4 & $38.5^{* *}$ & $11.8^{* *}$ & 56 \\
\hline
\end{tabular}

NOTE: * = significant at 0.1 level; ${ }^{* *}=$ significant at 0.05 level.

\section{Regression Analysis of Indiana Law Alumni Income and Job Satisfaction}

Our analysis of means has shown that our alumni's income and job satisfaction are associated with a number of variables including hours worked, type of practice, gender, race, and ethnicity. We have also seen that gender, race, and ethnicity may also play a role in the type of practice the alum may go into and the number of hours he or she may work. In order to separate the effects of these variables on income and job satisfaction, we need to use the statistical tool of linear regression analysis. Regression analysis estimates an equation explaining the dependent variable, for example income or job satisfaction, as a linear function of a collection of independent variables. The coefficients estimated for each independent variable express the marginal change in the dependent variable associated with a change in the independent variable, holding the other independent variables constant. The coefficients of the regression equation can be checked to see if they are significantly different from zero. In this way, we can examine the impact of each independent variable on the dependent variable while accounting for changes in the other independent variables. In this Part, we present the results of four regressions intended to isolate the effects of the variables gathered in our study on income and job satisfaction for both the classes of 1995-99 and the classes of 1985-89.

Table 22, regressions 3 and 4 estimate alumni income based on a traditional economic model of labor supply. ${ }^{37}$ Income is estimated as a function of work experience (years of practice), annual hours worked, annual hours of work squared, ${ }^{38}$ and a measure of productivity (law school GPA). The coefficients for these continuous independent variables express how much the respondents' incomes vary, on average,

37. See Dau-Schmidt \& Mukhopadhaya, supra note 26, at 359.

38. Using the square of yearly hours of work is accepted practice in such evaluations to identify nonlinear trends. The idea here would be that there are disproportionately increasing returns to additional time on the job. 
with a change in the independent variable. For example, the coefficient for "Law School GPA" expresses how much a respondent's income would go up or down with an increase in his or her GPA, all other variables held constant. Regression equations 3 and 4 also contain dummy variables for various labor-market characteristics (size of the city, region, and the type of practice) and for personal characteristics such as gender, race, and ethnicity that may be associated with various labor-market choices or opportunities. Equation $\mathbf{4}$ for the alumni fifteen years out of law school also includes dummy variables for whether the alum is working in a private firm in a position that is not that of partner, whether the alum has ever not worked or worked part time to do childcare, and whether he or she has a spouse with an intense job. A dummy variable is a categorical variable that is assigned the value of zero if the category does not apply to the respondent and one if it does. For example, the dummy variable "female" takes on the value zero if the respondent is a man and one if the respondent is a woman. The default case for these regressions, or the case in which all dummy variables are zero, is a non-Black, non-Hispanic, non-Asian male who works in a super private practice in a large city in the Midwest. In equation 4 for the alumni fifteen years out of law school you can add that the default is a partner, has never interrupted his or her career to do childcare, and does not have a spouse with an intense job. Accordingly, dummy variables for "male," "non-Black," "non-Hispanic," "non-Asian," "private practice super," "works in Midwest," "partner," "not interrupt career for child care," and "not have a spouse with an intense job" are omitted from the equations to avoid overidentification of the regression equation, and all coefficients on the remaining dummy variables are expressed in terms of variation from the default case. For example, the coefficient for female expresses how much more or less a woman earns than a comparably situated man and the coefficient for "works in east" expresses how much more or less a lawyer working on the East Coast would earn as compared with a comparably situated lawyer in the Midwest. All coefficients are expressed in thousands of 2004 dollars and can be tested to see whether the coefficients are significantly different from zero.

Table 22, regression 3 reports the results of the income regression for the classes of 1995-99 surveyed five years after law school. The results suggest that income is positively related to law school GPA $(\$ 36,147 \text { for a point on the alum's GPA })^{39}$ and living on the East and (perhaps) West Coasts ( $\$ 22,384$ and $\$ 26,384$, respectively) and negatively related to working in a medium or small city $(\$ 13,528$ and $\$ 12,213$, respectively). In addition, the results show that, even after correcting for hours and so forth, alumni in supersized private practices make significantly more money than alumni in any other type of practice, five years out of law school, except corporate counsel. In particular, on average, alumni in super private firms make $\$ 44,223$ more than government lawyers and $\$ 51,861$ more than public interest attorneys, even after correcting for hours, city size, region, and any differences in grades! Finally, the results suggest that, even a mere five years out of law school, women make significantly less than men-on average $\$ 6979$ less per year. None of the minority groups show income significantly lower than the majority five years out and indeed the coefficients for

39. Although this dollar amount is impressive, note that the difference of a whole GPA point represents a large difference in class standing and performance. In most law school classes, a jump in GPA from 2.7 to 3.7 would involve passing almost $80 \%$ of the graduating class. 
Black and Asian alumni are positive. Both the results with respect to gender and race are somewhat surprising, although they are consistent with the findings of other studies. ${ }^{40}$ For some time now, women have enjoyed educational opportunities that are superior to those of men, ${ }^{41}$ and, at least in our sample, initial job opportunities that are at least as good as men's, yet they end up earning almost $\$ 7000$ less than men a mere five years after graduation! Black alumni, who enjoy neither of these advantages, end up making more than their majority classmates, after correcting for differences in the examined independent variables, although the result is not statistically significant. It may be that women suffer more serious wage discrimination than Blacks, although it may also be that differences in personal characteristics and family roles between the genders contribute significantly to this result. Our simple efforts to untangle this puzzle with the available data were unsuccessful, ${ }^{42}$ although our results with respect to childcare and whether the alum's spouse has an intense job in regression 4 suggest that family roles play an important part. A more detailed decomposition analysis of the differences in income between the genders, including the estimation of separate regression equations for men and women, will have to wait until we have collected more data. $^{43}$

40. The negative result with respect to women is consistent with preliminary results obtained by Professor Joyce Sterling for the profession as a whole in a joint publication by the NALP Foundation for Law Career Research and Education and the American Bar Foundation: ROBERT DINOVITZER, BRyANT G. GARTH, RICHARD SANDER, JOYCE STERLING \& GITAZ. WILDER, After tHE JD: THE FIRST Results of A NATIONAL STUDY OF Legal Careers (2004), http://www.abf-sociolegal.org/NewPublications/AJD.pdf. The positive result with respect to Blacks is consistent with results from a study of Michigan Law alumni. See Richard O. Lempert, David L. Chambers \& Terry K. Adams, Michigan's Minority Graduates in Practice: The River Runs Through Law School, 25 J.L. \& SOC. INQUIRY 395, 447-53 (2000).

41. Since at least the mid-1980's girls have enjoyed significant advantages in primary education and have received the majority of university undergraduate degrees. DAN KINDLON \& MiCHAEL THOMPSON, RAIING CAIN: PROTECTING THE EMOTIONAL LIFE OF BOYS (2000); MiCHAEL Gurian \& Kathy STEVENS, THE MINDS OF Boys: SaVING OUR SONS From Falling BeHIND IN SCHOOL AND LIFE (2005). Today, women earn $57 \%$ of bachelor's degrees, $55 \%$ of master's degrees, $46 \%$ of doctorate degrees, and $48 \%$ of professional degrees. This trend is projected to continue through 2014. WILLIAM J. HuSSAR, NAT'LCTR. FOR EDUC. STATISTICS, U.S DEP'T OF Educ., Projections of Education Statistics to 2014, at 13 (2005), available at http://nces.ed.gov/pubs2005/2005074.pdf.

42. We tried adding some simple dummy variables for family characteristics to regression 3 , but got insignificant and counterintuitive results. We also considered running a regression just on unmarried alumni without children, but the sample was too small.

43. The insignificant and counterintuitive results we obtained with simple dummy variables for family characteristics in regression 3 are consistent with the idea that men's and women's income regression equations are qualitatively different with respect to these variables and should be estimated separately. For example, although on average children may reduce women's earnings as they struggle to cover both home and job, on average children probably increase men's earnings if they occupy a traditional bread-winning position as they struggle to earn more money for their family. By estimating the impact of children on income in one regression including both men and women, we confuse these divergent effects. The best way to address this problem is to estimate separate regression equations for both men and women and compare the estimated coefficients and differences in male and female sample means through a process called "decomposition analysis." Morley Gunderson, Male-Female Wage Differentials and Policy 
Table 22. Income regressions

\begin{tabular}{|c|c|c|c|c|}
\hline \multirow{2}{*}{$\begin{array}{l}\text { Dependent variable } \\
\text { Annual income (thousands of } 2004 \\
\text { dollars) }\end{array}$} & \multicolumn{2}{|c|}{$\begin{array}{c}\text { Regression 3: } \\
\text { Classes of 1995-99, } \\
\text { five years out }\end{array}$} & \multicolumn{2}{|c|}{$\begin{array}{c}\text { Regression 4: } \\
\text { Classes of 1985-89, } \\
\text { fifteen years out }\end{array}$} \\
\hline & Coefficient & $\begin{array}{l}\text { Signif. } \\
P>|t|\end{array}$ & Coefficient & $\begin{array}{l}\text { Signif. } \\
P>|t|\end{array}$ \\
\hline Years of practice & 1.471984 & .260 & $4.246179 * *$ & .000 \\
\hline Annual hours of work & .0095164 & .765 & -.0390857 & .577 \\
\hline Annual hours of work squared & $-7.43 e-07$ & .905 & .0000134 & .319 \\
\hline Law school GPA & $36.1471 *$ & .001 & 23.97644 & .312 \\
\hline Works in medium city & $-13.5279 * *$ & .001 & $-62.09627^{* *}$ & .000 \\
\hline Works in small city & $-12.21298^{* *}$ & .036 & $-52.78857^{* *}$ & .008 \\
\hline Works in East & $22.3843^{* *}$ & .004 & 32.67928 & .133 \\
\hline Works on West Coast & 26.03773 & .121 & 41.28686 & .162 \\
\hline Works in Southeast & 5.103777 & .495 & $-40.69509 * *$ & .020 \\
\hline Works in West & 3.531847 & .525 & -2.07286 & .911 \\
\hline Not partner, priv. prac. super & - ב...-- & -... & 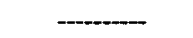 & - \\
\hline Private practice large & $-21.56768^{* *}$ & .011 & -40.119 & .252 \\
\hline Not partner, priv. prac. large & & $\cdots$ & & - \\
\hline Private practice medium & $-32.65927^{* *}$ & .000 & -62.69549 & .155 \\
\hline Not partner, priv. prac. medium & & -.-.- & & 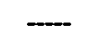 \\
\hline Private practice small & $-29.68214^{* *}$ & .001 & $-88.52083^{* *}$ & .018 \\
\hline Not partner, priv. prac. small & - & -...- & $-56.78997 * *$ & .020 \\
\hline Corporate counsel & -10.93558 & .313 & $-68.27961 *$ & .069 \\
\hline Government practice & $-44.22324 * *$ & .000 & $-127.5702 * *$ & .000 \\
\hline Public interest & $-51.86085^{* *}$ & .000 & $-139.8954^{* *}$ & .001 \\
\hline Other & $-34.15473 * *$ & .000 & $-87.06158 * *$ & .020 \\
\hline Female & $-6.978661 * *$ & .049 & -18.04356 & .243 \\
\hline Black & 8.701209 & .310 & 25.74134 & .424 \\
\hline Asian & 5.835216 & .474 & -26.17925 & .423 \\
\hline Hispanic & -11.66478 & .289 & $-101.5101 * *$ & .022 \\
\hline Not work or work part time, childcare & & - & $-37.20748^{*}$ & .062 \\
\hline Spouse has intense job & & -_-- & $-38.44956^{* *}$ & .006 \\
\hline Constant & -26.74443 & .585 & 185.2459 & .167 \\
\hline Regression summary statistics & $\begin{array}{l}\text { Number of obs. }= \\
F(21,235)=7.73 \\
\text { Prob. }>F=0.000 \\
\text { R-squared }=0.41 \\
\text { Root MSE }=29.7\end{array}$ & & $\begin{array}{l}\text { Number of obs. } \\
F(23,96)=-- \\
\text { Prob. }>F=- \\
\text { R-squared }=0.6 \\
\text { Root MSE }=60 .\end{array}$ & \\
\hline
\end{tabular}

NOTE: * = significant at 0.1 level; ** = significant at 0.05 level.

Table 22, regression 4 reports analogous results for the income regression of the classes of 1985-89 surveyed fifteen years out of law school. The results show patterns similar to those found for the classes of 1995-99 five years out of law school, except that some of the differences have grown and a few new patterns have emerged. In the income regressions for alumni fifteen years out of law school, income is now significantly positively correlated with years of practice, with each additional year of practice earning the alum, on average, $\$ 4246$ in additional income. This new pattern has probably emerged in the fifteen-year data because at fifteen years after law school, there is much more variation in the number of years of practice in the sample. Income

Responses, 27 J. ECON. LrT. 46 (1989). Unfortunately we do not yet have enough observations to estimate separate equations for men and women. 
is still positively related to law school GPA ( $\$ 23,976$ per point) and working on the East and West Coasts $(\$ 32,679$ and $\$ 41,287$, respectively), although these results are no longer statistically significant, while income is negatively related to working in a medium or small city $(\$ 62,096$ and $\$ 52,789$, respectively). The income advantage of alumni in supersized private practices over all other forms of practice has grown in the fifteen year data. They earn $\$ 88,521$ more than their classmates in small private practices, $\$ 127,570$ more than their classmates in government work, and $\$ 139,895$ more than their classmates in public interest practice! Men's earning advantage over women has grown to $\$ 18,044$ a year, but this result is no longer statistically significant, and our Hispanic alumni report earning $\$ 101,510$ less than their non-Hispanic classmates! The coefficient for Black alumni is still insignificantly positive in the fifteen-year data, and the coefficient for Asian alumni is insignificantly negative.

Although the coefficient for the female dummy variable suggests a male/female earnings differential of $\$ 18,044$ a year, this result is well short of the $\$ 80,600$ male/female earnings differential observed in the sample means reported in table 19 $(\$ 173,100 / \$ 92,500)$ and is not statistically different from zero. Examining the coefficients for the partnership and family characteristics dummy variables added to equation 4 explain much of the difference between the coefficient and mean values. The coefficient for not being a partner in a small private practice (the only nonpartnership dummy variable with observations in equation 4) suggests that working as something other than a partner in a small firm costs an alumni $\$ 56,790$ a year and this result is significant. Recall that, for all sizes of firms, our female alumni are more likely than their male counterparts to be working in a non-partnership position fifteen years after law school. Similarly, the coefficients for the dummy variables for whether the alum has ever not worked or worked part time to do childcare and whether he or she has a spouse with an intense job indicate that, on average, interruption of a career to do childcare lowers one's annual salary by $\$ 37,207$ and accommodating a spouse with an intense career lowers one's annual salary by $\$ 38,450$. Both of these results are statistically different from zero. As we have previously seen, our female alumni are much more likely than their male counterparts to interrupt their career to do childcare, and also more likely to have a spouse with an intense job. Finally, our female alumni on average work fewer hours a year than their male counterparts and tend to gravitate toward the types of practice that allow control over hours, but pay less, over the course of their careers-again, undoubtedly, to accommodate the demands of family. By presenting these results we do not mean to suggest that the male/female income differential among our alumni, or in the profession as a whole, is of no consequence, but only to present evidence that the indirect effects on women's average wages in the legal profession due to their childcare responsibilities appear much larger than any residual direct effect due to their identity as women. Based on the results of this survey, it appears that accommodating the demands of family and career is the primary obstacle to the advancement of our female alumni in the legal profession today.

Table 23, regressions 5 and 6 examine the effects of certain reported variables on overall job satisfaction. Once again, the basic theory of the regression equation is the economic model of labor supply. Job satisfaction is assumed to be a function of income, years of practice, annual hours worked, ${ }^{44}$ job stress, family satisfaction,

44. Again, following the traditional empirical economic model of labor supply, annual 
satisfaction with family/work balance, productivity (again represented by law school GPA), size of city in which the respondent works, region in which the respondent works, the type of practice in which the respondent works, whether the respondent is in private practice and not a partner, and possibly personal characteristics such as gender, race, and ethnicity. Again, the regression equation is made up of both "continuous variables" and "dummy variables." The "continuous variables" include income, years of practice, annual hours of work, job stress $(-3$ to +3$)$, family satisfaction $(-3$ to +3$)$, satisfaction with family/work balance $(-3$ to +3$)$, and law school GPA. ${ }^{45}$ The dummy variables include the size of city in which the respondent works, the region in which the respondent works, the respondent's type of practice, whether the respondent is in private practice and not a partner, and the respondent's personal characteristics such as gender, race, and ethnicity. Also, once again, the default for the regression equation is a non-Black, non-Hispanic, non-Asian male who works for a supersized private practice in a large city in the Midwest, so the coefficients for the remaining dummy variable express the increased or decreased job satisfaction in deviating from that default. In regression equation 6 for alumni fifteen years out of law school, we include dummy variables for whether the respondent is working in a private firm of a given size in a capacity other than partner, so for equation 6 the default scenario includes being a partner. The coefficients in the regression equation represent increases or decreases in expressed job satisfaction on the previously discussed seven point scale from "very unsatisfied" $(-3)$ to "very satisfied" $(+3)$. Once again, we can statistically test the coefficients to determine whether they are significantly different from zero.

hours of work squared is also included in the regression equation to account for possible nonlinear relations involving that variable.

45. The job stress and satisfaction variables are, of course, not strictly "continuous variables," because they can take on only seven discrete values. However, they are not binary variables like the dummy variables, and so, we include them with the "continuous variables" for the purposes of our explanation. 
Table 23. Job satisfaction regressions

\begin{tabular}{|c|c|c|c|c|}
\hline \multirow{2}{*}{$\begin{array}{l}\text { Dependent variable: Overall job } \\
\text { satisfaction }(-3 \text { to }+3)\end{array}$} & \multicolumn{2}{|c|}{$\begin{array}{l}\text { Regression 5: } \\
\text { Classes of 1995-99, } \\
\text { five years out }\end{array}$} & \multicolumn{2}{|c|}{$\begin{array}{l}\text { Regression 6: } \\
\text { Classes of 1985-89, } \\
\text { fifteen years out }\end{array}$} \\
\hline & Coefficient & $\begin{array}{l}\text { Signif. } \\
\mathrm{P}>|\mathrm{t}|\end{array}$ & Coefficient & $\begin{array}{l}\text { Signif. } \\
P>|t|\end{array}$ \\
\hline Income (in thousands of 2004 dollars) & $.0042012^{*}$ & .074 & $.0043824^{* *}$ & .000 \\
\hline Years of practice & .0309326 & .131 & -.0244086 & .270 \\
\hline Annual hours of work & -.0006793 & .481 & .001678 & .115 \\
\hline Annual hours of work squared & $1.83 \mathrm{e}-07$ & .327 & $-3.35 \mathrm{e}-07$ & .106 \\
\hline Job stress & $.1751655^{* *}$ & .006 & .0930803 & .167 \\
\hline Family satisfaction & $.1435312^{* *}$ & .023 & .0379179 & .511 \\
\hline Satisfaction with fam./wk. balance & $.1799083^{* *}$ & .005 & $.2065711 * *$ & .010 \\
\hline Law school GPA & -.2247307 & .434 & .5428526 & .104 \\
\hline Works in medium-sized city & .1923666 & .182 & .2520236 & .227 \\
\hline Works in small city & .2200994 & .246 & -.1005749 & .632 \\
\hline Works in East & .0569668 & .787 & $.448556^{*}$ & .075 \\
\hline Works on West Coast & $-.5980188^{*}$ & .098 & $-.551163^{*}$ & .100 \\
\hline Works in Southeast & -.1185689 & .525 & -.0439041 & .877 \\
\hline Works in West & .0908102 & .805 & .0176864 & .952 \\
\hline Not a partner, priv. prac. super & $-\cdots-\cdots$ & - & -.3743958 & .554 \\
\hline Private practice large & .0344283 & .908 & .4923677 & .381 \\
\hline Not a partner, priv. prac. large & & - & & - \\
\hline Private practice medium & -.4671903 & .115 & .5518144 & .237 \\
\hline Not a partner, priv. prac. medium & ---- & & - & ----- \\
\hline Private practice small & $-.5652826 * *$ & .021 & .6627104 & .151 \\
\hline Not a partner, priv. prac. small & & - & .1372552 & .624 \\
\hline Corporate counsel & -.1646503 & .466 & .3770127 & .438 \\
\hline Government practice & -.1535834 & .505 & $.995159 * *$ & .050 \\
\hline Public interest & -.0348585 & .912 & $1.112042^{* *}$ & .039 \\
\hline Other & -.3870865 & .109 & $1.040548^{* *}$ & .025 \\
\hline Female & -.1806923 & .175 & $.418306^{*}$ & .082 \\
\hline Black & .0328724 & .900 & .4080811 & .128 \\
\hline Asian & $-.576625^{* *}$ & .027 & $-1.145021^{* *}$ & .029 \\
\hline Hispanic & -.3030597 & .485 & $1.692998^{* *}$ & .000 \\
\hline Constant & 2.07988 & .162 & $-3.479071^{* *}$ & .028 \\
\hline Regression summary statistics & \multicolumn{2}{|c|}{$\begin{array}{l}\text { Number of obs. }=248 \\
F(25,222)=3.96 \\
\text { Prob. }>F=0.0000 \\
\text { R-squared }=0.3068 \\
\text { Root MSE }=0.96701\end{array}$} & \multicolumn{2}{|c|}{$\begin{array}{l}\text { Number of obs. }=134 \\
F(24,108)=-- \\
\text { Prob. }>F=- \\
\text { R-squared }=0.3617 \\
\text { Root MSE }=0.858925\end{array}$} \\
\hline
\end{tabular}

NOTE: * = significant at 0.1 level; $* *=$ significant at 0.05 level

Table 23, regression 5 reports the results from the classes of 1995-99 surveyed five years after graduation. Because the job satisfaction variable is measured on a relatively small seven point scale, we expect the sizes of the coefficients to be relatively small. However, with such a variable even small coefficients can be significant, ${ }^{46}$ and we test each coefficient as to whether it is statistically different from zero. The regression suggests that overall job satisfaction is positively correlated with income, job stress,

46. Recall that for the satisfaction variables, the standard deviation is generally about one point, so assuming a normal distribution, an increase of one point from the mean would leapfrog you over about $34 \%$ of the lawyers in the sample. 
family satisfaction, and satisfaction with family/work balance. With respect to income, the coefficient suggests that a $\$ 100,000$ increase in income will increase the average alum's job satisfaction at the mean by roughly .42 points and jump him or her over approximately $17 \%$ of the legal profession in terms of enjoyment of his or her job. The positive relationship between job satisfaction and job stress is a bit of a surprise, and we can only surmise that this is a spurious correlation between jobs that are satisfying and jobs that are stressful, and that stress itself does not increase job satisfaction. The positive relationships between job satisfaction, family satisfaction, and satisfaction with family/work balance are not a surprise, and suggest that one way for firms to increase the job satisfaction of their attorneys is to become more family friendly and improve the balance of work and family. ${ }^{47}$ Overall, job satisfaction is negatively associated with working on the West Coast, working for a small- (or medium-) sized firm, and being an Asian attorney five years out of law school.

Table 23, regression 6 reports the results from the classes of 1985-89 surveyed fifteen years after law school. Many of the trends observed for the classes of 1995-99 are discernable in this sample as well. Income is once again positively and significantly correlated with job satisfaction, and the reported coefficient is remarkably close to that for the five year survey. Satisfaction with family/work balance is also, once again, significantly and positively correlated with overall job satisfaction. However, there are also some interesting differences from the results in regression 5. For example, law school GPA is positively associated with job satisfaction in the fifteen year survey and just shy of statistical significance, while law school GPA shows an insignificant negative coefficient in the five year survey. This result may suggest that greater job productivity leads to greater job satisfaction over time. Similarly, working in a small (or medium) firm, government work, public interest work, or "other" work showed negative coefficients for job satisfaction in the five-year survey, but now show positive coefficients for job satisfaction in the fifteen-year survey. These results are statistically significant for government work, public interest work, and "other" work, and their coefficients of approximately 1 suggest that around the mean, alumni in these positions are about 40 percentile points higher in the job satisfaction distribution than their colleagues in supersized private firms. Perhaps the lawyers who do this work gain more control and prestige as they progress in these types of practices, or those who remain in these types of practices after fifteen years really take satisfaction in their work. In any event, the negative relationship between income and job satisfaction previously observed in University of Michigan law alumni ${ }^{48}$ also becomes apparent in this data on our alumni since the lower paid types of practice have coefficients suggesting significantly higher job satisfaction fifteen years out of law school. With respect to gender and minority groups, Asians continue to report being significantly less satisfied with their jobs fifteen years after graduation, while women and Hispanics report being

47. See Sheri A. Mullikin \& Anthony B. Taddeo, Jr., Balancing a Legal Career and Child Care in a 24/ World, FOR THE DEF., Jan 2001, at 38. The authors argue that by providing childcare, firms reduce turnover and absenteeism while increasing productivity and employee morale, and attracting more young professionals. There are a wide range of possible methods for employer involvement in employee childcare, ranging from in-house childcare to qualified dependent care assistance plans and beyond. The authors advocate that firms may enjoy positive benefits by addressing the dual concerns of work and family.

48. Dau-Schmidt \& Mukhopadhaya, supra note 26, at 346-47. 
significantly more satisfied with their work. Our Black alumni also have a positive coefficient with respect to job satisfaction fifteen years after graduation, but the result is just shy of statistical significance.

\section{CONCLUSION}

Our journey with our alumni has come to an end for now. In future research, we will analyze the data in greater detail, discussing not only trends observed in this article but also possible causes and implications of the trends. This journey has increased our understanding of what our students think of us after they leave law school, what they think of the law school experience, and how the law school experience has affected their lives. Additionally, we now have a better idea of who our alumni are, the types of practice in which they are found, and their income and satisfaction in the career and family opportunities they have enjoyed.

We find that our students are generally satisfied with their law school experience. Our alumni particularly found Constitutional Law and Torts intellectually satisfying, while they found Contracts and Civil Procedure the most useful in their careers. Using their experiences, and perhaps a touch of hindsight, our alumni suggest that the law school add more research and writing to the curriculum, perhaps to the chagrin of current and future students. Women seem particularly satisfied with their law school experiences, but there does not appear to be a correlation between race and the level of satisfaction with the law school experience. We did find that those in large private practices typically report higher levels of satisfaction with law school than those in other types of practice. Those working in government and public interest reported lower levels of satisfaction with law school at five years out, but that difference was less in the fifteen-year sample. Our regression results suggest that satisfaction with law school was positively associated with a student's grades and his or her participation on a journal or in moot court.

Although our alumni report satisfaction with the law school experience, that satisfaction comes at an ever-greater price. Our alumni from the classes of 1995-99 report roughly twice the average debt after law school as our alumni from the classes of 1985-89. The financing of education is a complex problem and students rely on a wide variety of resources to fund their education. Although there seems to be little difference in financing strategies between the genders, there does seem to be some difference in financing strategies based on race and ethnicity. Non-Blacks rely more heavily on private sources of funding, while Black students rely more heavily on university and government loans, grants, and scholarships. Hispanics rely more on employment than non-Hispanics. Interestingly, alumni who end up in large private practices rely more on spousal support in law school, and those who end up in medium and small firms rely the least on outside assistance. In the end, women and Blacks end up owing more money after law school and worry about repaying it more, along with our alumni in government and public interest practice.

The law school experience has an impact on the career plans of students. Although a large percentage of alumni end up working in precisely the type of practice they report having planned to pursue at the beginning of law school, there is a discernable drift during law school in favor of plans to work in private practice. This change in plans is perhaps largest among women, but is readily discernable across all demographic groups. From our results, we cannot determine whether this drift is due to law school 
socialization, the provision of information on careers, experience in summer jobs, or students merely giving in to the realities of the marketplace.

Our alumni also report great diversity in their personal and family characteristics. The men typically report themselves as being more aggressive than other lawyers, while the women believe themselves to be more compassionate. Interestingly, our minority alumni report being both more aggressive and more compassionate than their majority colleagues. Our male alumni report being relatively more concerned with money in their career, while our female and minority alumni report being relatively more concerned with social impact. Our male alumni are more likely to be married than our female alumni. Although there are many exceptions, our graduates typically organize their families in a somewhat traditional manner, as the men are typically the main (but not only) breadwinner, and the women are typically (but not solely) responsible for child care. On average, the spouses of our female alumni make much more than the spouses of our male alumni and are more likely to have an intense job. These differences in spousal income and career are especially true in the sample surveyed fifteen years after graduation.

These choices have profound implications on career paths. We find that women enter, and for at least five years remain in, private firms at a rate commensurate to men. Fifteen years after law school, however, women are not present in private practice in the same numbers as men. Men dominate large private practice, while women are found in greater proportion in positions in corporate counsel, government, and public interest practice, although the differences across gender in these positions are not significant. Also notable is the fact that many of our graduates do not go into traditional legal practice at all. Indeed, in our fifteen-year survey almost a third of our alumni report being in this "other" category. These alumni are judges, elected and appointed public officials, teachers, government employees, and (most often) business managers. The diversity of successful careers our alumni enjoy testifies to the talents of our alumni and the general value of a legal education.

In their chosen careers, our alumni generally practice law, earn decent wages, and are satisfied to do so. Our alumni in large private practices make significantly more money than any other kind of practice, except corporate counsel, and make almost twice as much as those in government and public interest practice, even five years out of law school. This advantage in income only grows in the survey fifteen years after graduation, with alumni in large private practices earning on average over three times as much as those in government and public interest practices. The relationship between job satisfaction and type of practice is less clear. Although the alumni in large private practices report higher job satisfaction five years out of law school, they report significantly lower job satisfaction fifteen years out of law school. Alumni satisfaction with family/work balance is much lower in large private practices in both surveys. The results of our regressions suggest that there is a negative relationship between income and job satisfaction in that the types of practices with high income suffer lower job satisfaction after correcting for other variables. Our male alumni enjoy significantly higher incomes than their female classmates, although the women report working fewer hours and being significantly happier with their families. The difference in income based on gender persists in our regression analysis, although the result is insignificant in the regression of the responses fifteen years after graduation and is much smaller than the decreases in income associated with not being a partner, interrupting one's career to do child care, or having a spouse with an intense job. These results suggest that the biggest obstacle for our female alumni in making further progress in the legal 
profession is balancing family responsibilities with work. The coefficient for women in our regression for job satisfaction suggests that women are significantly happier with their jobs than men fifteen years after law school. Among our minority alumni, our Black alumni report earning significantly less income five years out of law school and less income fifteen years out of law school, although the latter difference is not statistically significant. Blacks and Hispanics report being significantly more satisfied with their jobs than their majority classmates fifteen years out of law school. Our regression analysis suggests that Blacks do not earn significantly less after correcting for various personal and labor-market characteristics, and that Hispanics earn significantly less than non-Hispanics fifteen years out of law school.

By their very nature, professors and law school administrators believe they will positively impact their students, who will in turn graduate successfully and trek off on the road to successful legal careers. For many, this belief was a powerful driving force that led them into the field of education. As the law school faculty watch the class of 2006 graduate in the spring, they can do so secure in the knowledge, verified by this empirical study, that the vast majority of those graduates will leave the Indiana University School of Law-Bloomington and go on to successful professional careers and meaningful family lives. They will look back on their time at Indiana largely satisfied and prepared for the challenges that await them. Our graduates, for their part, will enter the legal profession and navigate their professional challenges with skill and confidence. They will raise successful families and enjoy the fruits of their professional labor. For all of their efforts and successes, and whenever they choose to do so, they can certainly return to our academic home in Bloomington as the pride of Indiana. 